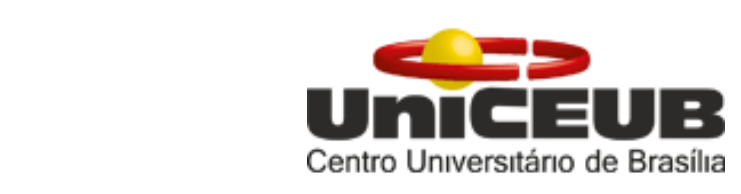

Centro Universitário de Brasília - UniCEUB

Programa de Iniciação Científica

VITOR DE CASTRO CABRAL

FERNANDA DE CARVALHO BRAGA

CUIDADOS PALIATIVOS PEDIÁTRICOS: PERCEPÇÕES DE PAIS E/OU CUIDADORES DO CUIDADO NO FINAL DE VIDA

BRASÍLIA

2018 


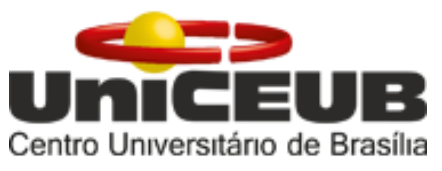

VITOR DE CASTRO CABRAL

FERNANDA DE CARVALHO BRAGA

\title{
CUIDADOS PALIATIVOS PEDIÁTRICOS: PERCEPÇÕES DE PAIS E/OU CUIDADORES DO CUIDADO NO FINAL DE VIDA
}

\author{
Relatório final de pesquisa de Iniciação Científica \\ apresentado à Assessoria de Pós-Graduação e \\ pesquisa.
}

Orientador: Neulânio Francisco de Oliveira

\section{Brasília}




\title{
CUIDADOS PALIATIVOS PEDIÁTRICOS: PERCEPÇÕES DE PAIS E/OU CUIDADORES DO CUIDADO NO FINAL DE VIDA
}

\author{
Vitor de Castro Cabral - UniCEUB, PIC instituicional, aluno bolsista \\ vitordeccabral@gmail.com
} Fernanda de Carvalho Braga - UniCEUB, PIC instituicional, aluna voluntária
braga.fernanda.carvalho@gmail.com

\begin{abstract}
Neulânio Francisco de Oliveira - UniCEUB, professor orientador neulanio.oliveira@uniceub.br
\end{abstract}

O cuidado pediátrico deve ser baseado na tríade paciente-família-profissional de saúde, uma vez que, nessa fase do desenvolvimento a tomada de decisão, muitas vezes, fica mais a cargo da família. Estabelecer uma comunicação efetiva entre pais e profissionais da saúde possibilita aos cuidadores maior conhecimento em relação ao paciente, permitindo, assim, que possa tomar parte nos processos decisórios do tratamento. O objetivo da pesquisa foi conhecer a percepção dos pais e/ou cuidadores, no que diz respeito a qualidade dos cuidados oferecidos aos pacientes internados em uma Unidade de Terapia Intensiva Pediátrica (UTIP) de referência do Distrito Federal. A pesquisa foi realizada na Unidade de Tratamento Intensivo Pediátrico no Hospital Materno Infantil de Brasília. Para coletar informações, foi adaptado o instrumento "Quality of Children's End-of-Life Care" (WIDGER et al, 2015) em escala de Likert, adequando-o à realidade do serviço em que a pesquisa foi realizada. Além disso, realizou-se entrevista semiestruturada para abarcar a percepção dos entrevistados sobre a assistência recebida durante a internação. Participaram da pesquisa 35 cuidadores, $94,3 \%$ pais e $5,7 \%$ outros familiares, sendo $80 \%$ mulheres e $20 \%$ homens. Sessenta por cento dos internados eram lactentes, $20 \%$ pré-escolares, $5,7 \%$ escolares e 14,2\% adolescentes. Das patologias que motivaram a internação, 48,6\% eram agudas, 28,6\% congênitas e 22,9\% crônicas. Dos sintomas presentes na internação, analisou-se dor, náuseas/vômitos, dificuldades respiratórias, sangramentos, convulsões, tristeza, ansiedade e medo, em variados graus, bem como a satisfação quanto ao controle destes. Quanto à satisfação dos entrevistados, $25,7 \%$ classificou a qualidade dos cuidados ao paciente como bom, $34,3 \%$ como muito bom e $40 \%$ como excelente. Na parte qualitativa, as respostas foram separadas em categorias: atenção da equipe; procedimento; profissional, ambiente da UTIP; más notícias; recuperação; cuidado da equipe; e qualidade da unidade de saúde. Essas referem-se à percepção dos entrevistados como melhor, pior ou mais importante evento durante a internação. Avaliação de como cuidadores percebem a assistência oferecida ao paciente é valiosa para auxiliar no estabelecimento de uma terapia. Utilizar um instrumento estruturado para mensurar a qualidade do serviço pode auxiliar profissionais de saúde a verificar pontos a serem aprimorados no serviço.

Palavras-chaves: Unidade de Terapia Intensiva Pediátrica. Pais e/ou cuidadores. Qualidade do cuidado. 


\section{LISTA DE ABREVIAÇÕES}

ABCP Associação Brasileira de Cuidados Paliativos 5

ANCP Associação Nacional de Cuidados Paliativos 5

UTI Unidade de Terapia Intensiva $\quad 7$

DF $\quad$ Distrito Federal $\quad 7$

$\begin{array}{lll}\text { UTIP } & \text { Unidade de Terapia Intensiva Pediátrica }\end{array}$

CCP Cuidados Paliativos Pediátricos 8

AAP American Academy of Pediatrics $\quad 10$

PIC Programa de Iniciação Científica $\quad 12$

UniCEUB Centro Universitário de Brasília 12

CEP Comitê de Ética em Pesquisa $\quad 12$

SES-DF Secretaria de Saúde do Distrito Federal $\quad 12$

HMIB Hospital Materno Infantil de Brasília 12

TCLE $\quad$ Termo de Consentimento Livre e Esclarecido 12

$\begin{array}{lll}\text { VA } & \text { Válvula aórtica } & 15\end{array}$

$\begin{array}{lll}\text { GTT } & \text { Gastrostomia }\end{array}$

IRpA Insuficiência Respiratória Aguda 15

PO Pós-operatório 15

ECNP $\quad$ Encefalopatia Crônica Não Progressiva 15

JUP Junção Ureteropélvica $\quad 15$

$\begin{array}{lll}\text { FBE } & \text { Fístula Broncoesofágica } & 15\end{array}$

$\begin{array}{lll}\text { TA } & 15\end{array}$

N Número de participantes $\quad 41$ 
SUMÁRIO

1. INTRODUÇÃO

2. FUNDAMENTAÇÃO TEÓRICA

3. METODOLOGIA 111

3.1. Tipo de estudo 111

3.2. Procedimento geral e população 111

3.3. Instrumento e variáveis 122

4. RESULTADOS E DISCUSSÃO

5. CONSIDERAÇÕES FINAIS 39

REFERÊNCIAS $\quad 400$ 


\section{INTRODUÇÃO}

Os princípios dos cuidados paliativos estiveram sempre presentes durante a história. Na Idade Média, o cuidado aos doentes com e sem perspectiva de cura era de responsabilidade da Igreja. Já no século XIX, formaram-se os primeiros espaços exclusivos para o atendimento dos pacientes fora de possibilidade terapêutica de cura. Entretanto, apenas na década de 1960, com a fundação do St. Christopher Hospice, no Reino Unido, por Cicely Saunders, que tais unidades passaram a representar a assistência paliativa e, hoje, espalham-se pela Europa e América do Norte (DA SILVA, 2012).

Condutas no final de vida auxiliam a todos que possuem doenças em estágio avançado, progressivas e incuráveis a viver tão bem quanto possível até que venham a falecer (JOHNSON, 2009). Neste sentido, a Organização Mundial de Saúde (OMS), propõe a definição da terapia paliativa como a abordagem de pacientes que enfrentam enfermidades que ameacem sua vida, visando promover qualidade de vida. $O$ foco terapêutico é o manejo de sintomas que prejudiquem o bem-estar global, sejam físicos, psicossociais e/ou espirituais (MACIEL et al, 2006).

No Brasil, a introdução do modelo paliativista ocorreu na década de 1980, com a incorporação da filosofia no "Serviço de Dor" do Hospital das Clínicas de Porto Alegre, em 1983 (MENDONÇA, 2012). Desde então, os princípios se espalharam pelo país, culminando com a criação da ABCP, em 1997, e da ANCP em 2005. A fundação dessas organizações contribuiu para a divulgação e otimização da área na realidade brasileira (HERMES \& LAMARCA, 2013).

Doenças crônicas ou terminais, que têm como desfecho o falecimento do paciente, podem acometer pacientes em diferentes fases de desenvolvimento (BRAGA, 2013). A abordagem pediátrica possui peculiaridades, uma vez que o desenvolvimento cognitivo e emocional da criança está ainda em construção, o que pode limitar a percepção de sua condição (MEYER et al, 2002). Sendo assim, nem sempre o paciente faz parte do processo de tomada de decisão sobre a conduta terapêutica, seja em razão de sua imaturidade, ou pelo impacto de sua doença. Logo, pais e/ou cuidadores tornam-se fundamentais nesse processo (WIDGER et al, 2015).

A participação dos familiares ou dos cuidadores reforça a aplicação e manutenção de uma terapia integral, especialmente diante de uma de uma doença incurável (LAGO, GARROS \& PIVA, 2010). Além disso, permite-se aos pais e/ou 
cuidadores paz de espírito e sensação de controle, possibilitando a redução de seu sofrimento (LOTZ et al, 2016). Porém cuidar de uma criança enferma traz uma elevada exigência física e emocional, que pode implicar em prejuízos à saúde do cuidador (GULDIN et al, 2012). Então, o processo de decisão do plano terapêutico deve envolver tanto a família quanto a equipe médica, sendo esta responsável por sua mediação (PIVA, GARCIA \& LAGO, 2011).

Pais, familiares ou representantes legais da criança envolvidos no processo de cuidado e tratamento do paciente participam nas tomadas de decisão com base nas informações fornecidas pelos profissionais de saúde (JANVIER, BARRINGTON \& FARLOW, 2014). Portanto, percebe-se a necessidade do compartilhamento de informações e concordância entre família ou representante legal e a equipe de saúde, como enfatiza e determina o atual código de ética médica (PIVA, GARCIA \& LAGO, 2011).

Os princípios que regem as medidas paliativas defendem que deve se iniciar o cuidado no momento do diagnóstico de uma doença, cujo curso natural seja o óbito. Apesar disso, o início das práticas paliativas tem ocorrido somente após o cessamento de todas as possibilidades curativas, o que sugere que falta ao profissional de saúde o conhecimento teórico e técnico de sua aplicação, como afirmam os autores Piva, Garcia e Lago (2011).

Os cuidados voltados aos momentos finais da vida estão intimamente relacionados com o tema da morte, que ainda é um tabu na sociedade principalmente em relação à infância. De acordo com Ferreira (2011), o falecimento de uma criança é visto como algo anormal, incomum, uma vez que ela ainda não vivenciou todas as fases do desenvolvimento. Apesar disso, pacientes pediátricos são diagnosticados com doenças ameaçadoras da vida e necessitam de assistência paliativa.

O processo de tomada de decisão sobre a terapia do paciente pediátrico é diferenciado do adulto, uma vez que, dependendo das condições cognitivas e psicológicas da criança, os pais e/ou cuidadores se tornam os atores principais da ocasião. Como afirma Cunha (2007), a família e/ou o cuidador é o principal personagem ao longo do percurso do paciente, já que acompanha de perto as consultas, exames e proporciona o ambiente para o enfrentamento da enfermidade. Além disso, familiares e/ou cuidadores são os responsáveis em apresentar à equipe de saúde os desejos do paciente sobre a terapêutica do final da vida.

A UTI é o setor onde se oferece cuidados a pacientes em estado crítico, com 
objetivo de manter a funcionamento orgânico e restabelecer a saúde (COOK; ROCKER, 2016). Apesar de todos os esforços, a morte é uma realidade comum nesse ambiente. Desse modo, é importante que o profissional de saúde esteja preparado para lidar com o final da vida, de modo que seja possível oferecer uma morte digna ao paciente (COOK; ROCKER, 2016).

No ambiente tecnológico de uma UTI, a morte digna pode ser associada com um cuidado que respeita a individualidade e a realidade do paciente (COOK; ROCKER, 2016). Os princípios dos cuidados paliativos são ferramentas a ser utilizados nesses momentos. Segundo Cook e Rocker (2016), no cuidado com o paciente internado em UTI, a paliação deve ser percebida como algo tão importante quanto prevenção e tratamento.

Cuidados paliativos constituem uma filosofia recente dentro da área da Medicina no Brasil e no mundo. Apesar do número de trabalhos sobre o tema ter aumentado na última década, ainda há muito a ser estudado e avaliado. O cuidado voltado a pacientes fora de possibilidade terapêutica curativa no DF é uma realidade ainda mais recente e que conta com pouquíssimos trabalhos sobre sua realidade. $O$ objetivo da pesquisa foi conhecer a percepção dos pais e/ou cuidadores, no que diz respeito a qualidades dos cuidados oferecidos aos pacientes em final de vida, em uma UTIP de referência do DF. 


\section{FUNDAMENTAÇÃO TEÓRICA}

A discussão sobre CPP deve ser pensada como peça fundamental no cuidado a crianças com enfermidades que ameaçam sua vida e seus familiares (BERINGER \& HECKFORD, 2012). Existe uma lacuna mundial sobre como e onde essa terapia tem sido oferecida, assim como do número real de crianças que necessitam de terapia paliativa. O estudo de CONNOR, DOWNING \& MARSTON (2017) traz uma estimativa de que, na população mundial, mais de 21 milhões de crianças são acometidas com doenças ameaçadoras da vida e cerca de 8 milhões são candidatas a receber cuidados paliativos.

A realidade brasileira não se afasta muito da global, guardadas as devidas proporções, estima-se que 500 mil crianças apresentam diagnóstico de doenças crônicas e mais de 180 mil apresentam critérios de elegibilidade para terapêutica paliativa (CONNOR, DOWNING \& MARSTON, 2017). As causas mais prevalentes de mortalidade infantil no Brasil no ano de 2016 foram afecções originadas no período perinatal (57\%) e malformações congênitas, deformidades e anomalias cromossômicas (22\%) (SIM-MS, 2016). No DF, ocorreram cerca de 2500 notificações de óbito, sendo $67 \%$ devido a afecções originadas no período perinatal.

Em meio a essa realidade, é necessário identificar quais enfermidades em que somente o tratamento curativo não abarca o cuidado necessário ao paciente. Mesmo sendo a terapia paliativa introduzida, geralmente nos momentos finais de vida, sua aplicação não deve ser restrita à terminalidade (KLICK \& HAUER, 2010). A proximidade da morte como requisito necessário vai de encontro com o princípio estabelecido pela OMS que diz:

"Ser aplicável no inicio do curso da doença, em conjunto com outras terapias que prolonguem a vida, como quimio e/ou radioterapia, e incluir investigações necessárias para o melhor entendimento e abordagem das complicações clínicas que causam sofrimento" (WHO, 2017).

Desse modo, a elegibilidade dos pacientes engloba doenças crônicas que ameacem à vida ou terminais (American Association of Pediatrics, 2000; HILMELSTEIN, 2006). São enfermidades que podem demandar o cuidado paliativo: HIV/SIDA; câncer; doenças cardiovasculares; anormalidades congênitas; cirrose hepática; alterações endócrinas, hematológicas e imunes; doenças renais; meningite; má nutrição; alterações neurológicas; condições neonatais limitantes da vida; 
tuberculose resistente a drogas (CONNOR; DOWNING; MARSTON, 2017; VALADARES; MOTA; OLIVEIRA, 2013).

Diferente do que se defendia durante a Idade Média, a criança não é um adulto em miniatura, ela apresenta aspectos específicos dessa fase do desenvolvimento humano (ÁRIES, 2003). As características físicas, psíquicas e cognitivas ainda estão em processo de construção durante a infância, por isso é importante compreender as aquisições de cada período para escolher a intervenção mais apropriada (BARBOSA, 2013).

Todas essas peculiaridades influenciam no cuidado a ser oferecido. O curso da doença, duração e prognóstico, é influenciado pelas variáveis do desenvolvimento e o tempo da oferta do cuidado será baseado nessas informações (CONNOR, DOWNING \& MARSTON, 2017). Percebe-se, então, a necessidade de estudos mais específicos sobre o cuidado ofertado ao final da vida para crianças, pois muitos dos protocolos atuais de CPP são baseados em estudos com a população adulta (MILLER et al, 2015).

Outro aspecto relevante é compreender que a criança pode fazer parte do processo decisório terapêutico, caso ela esteja em condições físicas, psíquicas e cognitivas. Apesar disso, na grande maioria dos casos, os pais e/ou cuidadores são as pessoas que participam e decidem o curso do cuidado (BARBOSA, 2013). Sendo assim, é importante compreender as necessidades dos familiares, além das demandas do paciente.

Quando se começa a pensar na introdução de uma terapêutica paliativa, a família é comunicada e solicita-se sua participação nos planos de fim de vida, garantindo-lhe suporte, inclusive em caso de irreversibilidade (LAGO, GARROS \& PIVA, 2010). Tais planos são compostos por discussões sobre os valores e preferências da família e/ou cuidador quanto aos cuidados oferecidos em saúde, visando entrar em concordância com as decisões terapêuticas a ser tomadas (LOTZ et al, 2016).

Cuidar de uma criança com uma doença limitante pode levar à instabilidade psicossocial (KNAPP et al, 2010). Os pais e/ou cuidadores estão sujeitos a vivenciar extremos emocionais, isso porque, ao longo do curso da doença, melhoras e recaídas dos filhos podem gerar tanto paz de espírito, como depressão (FEUDTNER et al, 2010; LOTZ et al, 2016; AL-GHARIB, ABU-SAAD HUIJER \& DARWISH, 2015; GULDIN et al, 2012). Frente à morte do paciente, o luto familiar deve ser 
acompanhado, já que, frequentemente, provoca choque, sensação de desamparo e sentimento de culpa, afetando relações interpessoais, o que pode resultar em isolamento, angústia, e morbidades físicas e psicológicas (SNAMAN et al, 2016).

A fim de abarcar todas os aspectos que envolvem os CPP, a AAP sugeriu cinco princípios que devem ser seguidos nessa abordagem: (1) respeito à dignidade dos pacientes e de seus familiares; (2) acesso a um serviço competente e compassivo; (3) serviço com suporte aos profissionais de saúde; (4) melhora do suporte social e profissional para os Cuidados Paliativos em pediatria; e (5) melhora contínua dos CCP, através da pesquisa e educação (American Academy of Pediatrics, 2000). Dessa forma, nota-se a contínua necessidade de entendimento acerca da efetividade de cuidados paliativos pediátricos, promovendo-se desenvolvimento e divulgação de informações sobre a área.

Todavia, muitos estudos sobre cuidados paliativos se baseiam apenas em índices de mortalidade (CONNOR, DOWNING \& MARSTON, 2017). Assim, encorajase a avaliação de cuidados de fim de vida a partir de múltiplas variáveis, como sequelas físicas e psicológicas, as percepções da criança e de sua família, e indicadores de cuidados de alta qualidade (NAMACHIVAYAM et al, 2010; WIDGER et al, 2015).

Contudo, há escasso direcionamento para se conduzir um estudo apropriado em situações de fim de vida (STEVENS et al, 2010). Nesse sentido, tratar com familiares e/ou cuidadores, tópicos sensíveis relativos a doenças severas, períodos de sofrimento e morte, é uma tarefa de difícil abordagem (MILLER et al, 2015).

Devido à grande importância dada à compreensão das experiências vividas por famílias e/ou cuidadores, que participam da dinâmica de cuidados paliativos, deve-se utilizar uma ferramenta confiável e válida para sua mensuração (WIDGER et al, 2015). Dessa maneira, possibilita-se a utilização de um método para avaliar a qualidade dos cuidados proporcionados em fim de vida numa abordagem pediátrica. 


\section{METODOLOGIA}

\subsection{Tipo de estudo}

Trata-se de um estudo observacional e transversal. $\mathrm{Na}$ pesquisa, os pesquisadores tiveram o papel de expectadores, sem interferir no processo, apesar de ser capazes de agregar informações para compreender o fenômeno, por isso denomina-se observacional (FONTELLES, SIMÕES, FARIAS \& FONTELLES, 2009). Foi transversal, pois captou as informações do contexto de forma instantânea (ROUQUAYROL \& ALMEIDA FILHO, 2006).

\subsection{Procedimento geral e população}

Para a realização da pesquisa, foi elaborado um projeto especificando os objetivos e os procedimentos necessários para sua realização. Esse documento foi analisado e aceito pelo PIC-UniCEUB. Além disso, foi aprovado pelo CEP/UniCEUB e pelo CEP/SES-DF sob o número de CAAE (75065517.8.0000.0023). A pesquisa foi realizada na UTIP no HMIB.

Após a aprovação do projeto pelos CEP, os pais e/ou cuidadores foram convidados a participar do estudo. Cada pai, mãe e/ou cuidador recebeu o TCLE para que estivessem cientes das características da pesquisa e dos direitos que eles, como participantes, possuem, inclusive de não responder a pesquisa, caso não se sentissem confortáveis para tal. Participaram do trabalho somente aqueles que leram e assinaram o documento.

Os critérios de inclusão foram:

1. Ser pai, mãe ou cuidador de paciente em faixa etária pediátrica admitido na UTIP do HMIB no período de novembro de 2017 a abril de 2018;

2. Ser pai, mãe ou cuidador de paciente que morreu na UTIP do HMIB no período de maio a outubro de 2017;

3. Ter tempo de internação na UTIP maior que 48 horas.

Os critérios de exclusão foram:

1. Ser pai, mãe ou cuidador de paciente internados em condição de coma permanente;

2. Familiares de paciente internado ou que morreu na UTIP em situação de abandono; 
3. Ser pai, mãe ou cuidador que tenha solicitado não manter contato com o hospital após a morte do paciente.

Para composição da amostra, o convite foi feito para os pais, mães e/ou cuidadores de pacientes internados na UTIP do HMIB no período de novembro de 2017 a abril de 2018. Eles foram convidados, pessoalmente, após o período de visita aos filhos, sendo que a maioria se disponibilizou a realizar a pesquisa logo após o convite.

A maioria dos pais e/ou cuidadores preferiu responder a pesquisa à beira leito. Todos responderam ao instrumento elaborado para o trabalho, porém 12 participantes não se sentiram à vontade de realizar a entrevista. $O$ tempo médio para responder os instrumentos foi de 40 minutos.

Além disso, seriam convidados os pais, mães e/ou cuidadores de pacientes que morreram no período de maio a outubro de 2017 na unidade. O contato seria realizado apenas após um período de, no mínimo, um mês decorrido desde o óbito do paciente. Devido a dificuldades durante o curso da pesquisa, essa etapa não pôde ser realizada.

Vale salientar que os participantes tiveram o direito de recusa à participação em qualquer uma dessas etapas, sem que houvesse prejuízo para eles. O sigilo das respostas e da identidade do respondente serão garantidos e o material de resposta está arquivado em local apropriado sob responsabilidade dos pesquisadores.

\subsection{Instrumento e variáveis}

Para coletar as informações, foi adaptado o instrumento "Quality of Children's End-of-Life Care" para o presente estudo. Ele é dividido em dez domínios, os quais abarcam diferentes aspectos do cuidado no final da vida: conexão com família; envolvimento dos pais; compartilhamento de informação com os pais; compartilhamento de informação entre profissionais de saúde; suporte à criança; suporte a irmãos; suporte aos pais; cuidado à morte; acompanhamento durante o luto; estruturas do cuidado; e qualidade geral.

A fim de contemplar os objetivos da pesquisa, os domínios suporte aos irmãos, estruturas do cuidado e suporte ao luto foram retirados. Além disso, alguns itens foram excluídos ou modificados para se adequar o instrumento à realidade da estrutura do serviço de saúde em que a pesquisa foi realizada.

Utilizou-se, ainda, um roteiro de entrevista semi-estruturado, a fim de conhecer 
a percepção dos pais e/ou cuidadores sobre a assistência recebida durante a internação e obter o perfil da amostra. As entrevistas foram gravadas, conforme consentimento dos sujeitos, e transcritas posteriormente.

A análise de dados quantitativos foi realizada por meio do programa Excel, que gerou os dados descritivos das respostas ao instrumento. Já as respostas coletadas pela entrevista semi-estruturada foram tratadas pelo método de análise de conteúdo de Bardin (2010), que gerou categorias referentes a cada questionamento. 


\section{RESULTADOS E DISCUSSÃO}

Durante o período da pesquisa, foram internados 160 pacientes na UTI pediátrica, sendo que participaram da pesquisa os pais e/ou cuidadores de 33 crianças. No total, o instrumento foi respondido por 35 familiares, sendo $80 \%$ mulheres e $20 \%$ homens com média de idade de 31,5 anos. Trinta e três participantes eram pais ou mães das crianças internadas e dois eram cuidadores (outros familiares), sendo que dentre eles $46,7 \%$ são casados, 33,3\% solteiros e $20 \%$ em união estável.

No que diz respeito ao número de filhos, $31,4 \%$ dos entrevistados possuem um filho, $34,3 \%$ dois filhos, $22,9 \%$ três filhos, $8,6 \%$ quatro filhos e $2,9 \%$ sete filhos. No que concerne ao nível educacional, $42,9 \%$ tinham ensino médio completo, $17,1 \%$ ensino médio incompleto, $11,4 \%$ ensino fundamental incompleto, $8,6 \%$ ensino superior incompleto, $8,6 \%$ ensino superior completo, 5,7\% ensino fundamental completo e $5,7 \%$ analfabetos. Além disso, $51,4 \%$ se declararam católicos, $40 \%$ evangélicos, $2,9 \%$ espírita, 2,9\% Adventista do $7^{\circ}$ dia e 2,9\% Agnóstico.

A religiosidade e a espiritualidade possuem papel importante na relação da família com os cuidados do paciente pediátrico. O significado atribuído a doenças críticas, particularmente quando a morte aparece, é frequentemente interpretado através de uma lente espiritual (COOK; ROCKER, 2016). Para muitas pessoas, a doença crítica desencadeia questões existenciais sobre propósito de vida, de morte e de sofrimento; sobre relacionamentos, sejam passados, presentes ou futuros; ou sobre destino (COOK; ROCKER, 2016).

Espiritualidade e religiosidade fazem parte dos princípios dos cuidados paliativos, como estabelecido pela Organização Mundial da Saúde e deve ser levada em consideração quando oferecido o cuidado (WHO, 2017). Além disso, religião e espiritualidade são considerados, pelos pais dos pacientes, como importantes fatores nas decisões de fim de vida, obtenção de paz e encontro de significado no falecimento do paciente (KELLY, MAY; MAURER, 2016). Os clínicos devem entender como a espiritualidade pode influenciar o enfrentamento, de forma positiva ou negativa (COOK; ROCKER, 2016).

Em relação às crianças internadas, $60 \%$ eram lactentes, $20 \%$ pré-escolares, $6 \%$ escolares e $14 \%$ adolescentes. Além disso, $51 \%$ apresentava doença de base e 49\% era hígido antes da internação. O motivo da internação e as doenças de base responsáveis pela estadia dos pacientes no nosocômio encontram-se nas Figuras $1 \mathrm{e}$ 
2. Dessas patologias, $48,6 \%$ são caracterizadas como agudas, $28,6 \%$ congênitas e $22,9 \%$ crônicas.

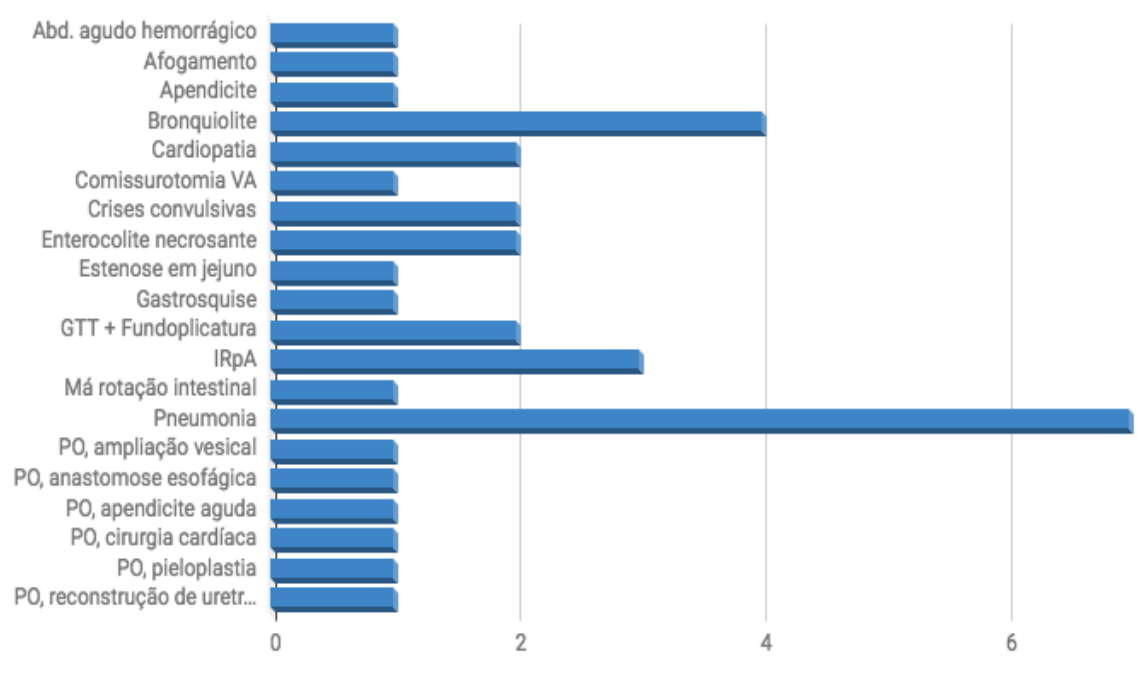

Figura 1: Motivos da internação

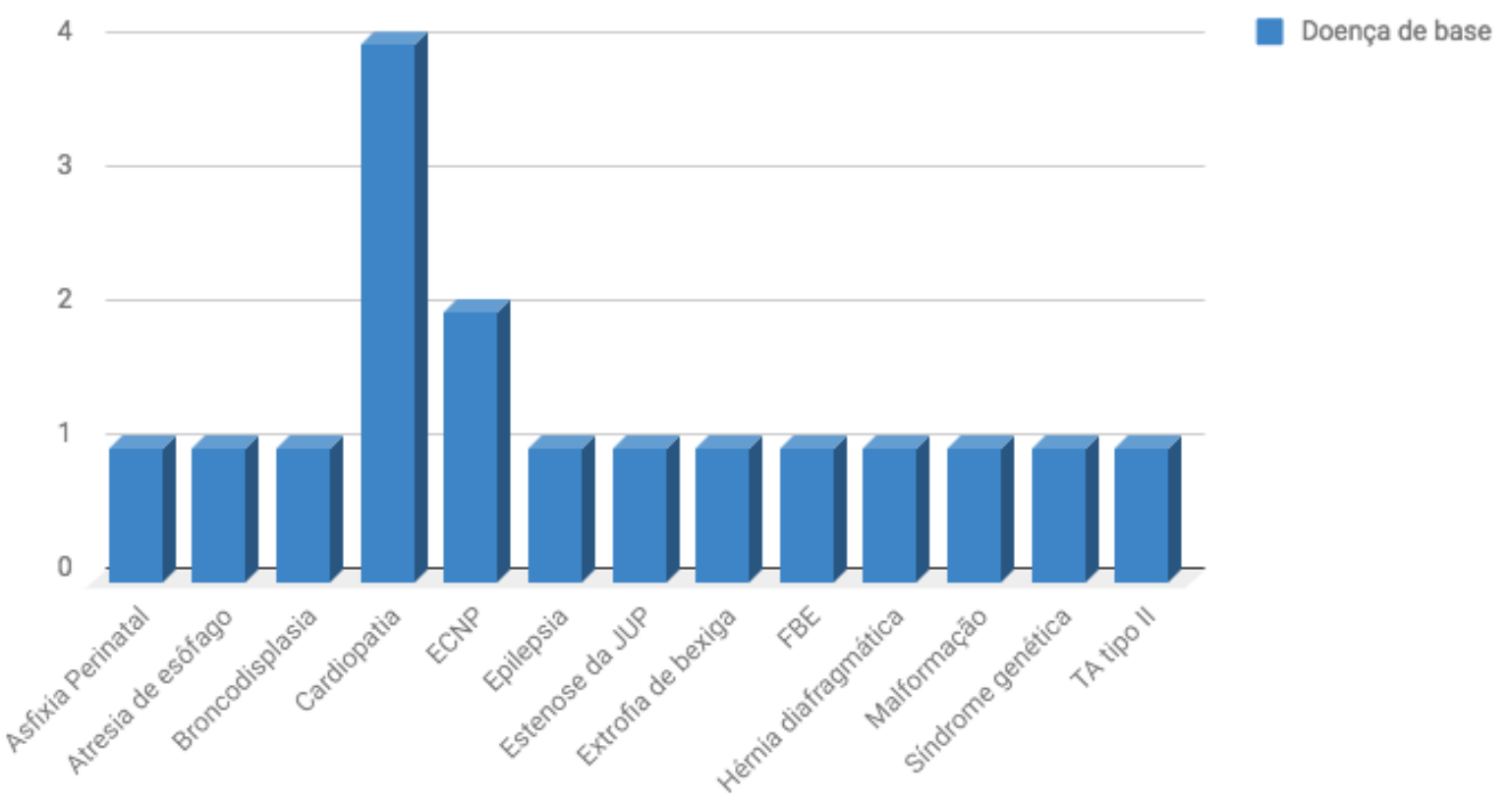

Figura 2: Doenças de base

Durante o período da pesquisa, 5\% pacientes internados na UTIP tiveram seus casos discutidos para entrada em cuidados paliativos. Apesar da filosofia paliativa estar bem difundida entre os profissionais de saúde, oferecer tais cuidados desde o diagnóstico da doença ainda apresenta obstáculos. 
Segundo BERGSTRAESSER, HAIN e PEREIRA (2013), o cuidado paliativo é introduzido tardiamente na trajetória de uma doença limitante. Eles citam como fatores limitantes a superestimação das chances de controle da doença ou sua cura; a relutância em aceitar o agravamento de uma doença e possível proximidade da morte; a preocupação com o entendimento da família sobre o significado de terapia paliativa. Além disso, alguns profissionais podem se sentir pressionados por familiares a oferecer tratamentos fúteis, pois estes podem considerar qualquer alternativa como uma desistência (BERGSTRAESSER; HAIN; PEREIRA, 2013).

O questionário utilizado avalia diferentes Domínios sobre o atendimento à criança internada, segue a análise realizada com os respondentes. O primeiro domínio refere-se à conexão com a família, onde se avalia a relação dos entre os familiares e/ou cuidadores e os profissionais de saúde. As figuras de 3 a 12 ilustram suas respostas:

Domínio 1 - Conexão com a família:

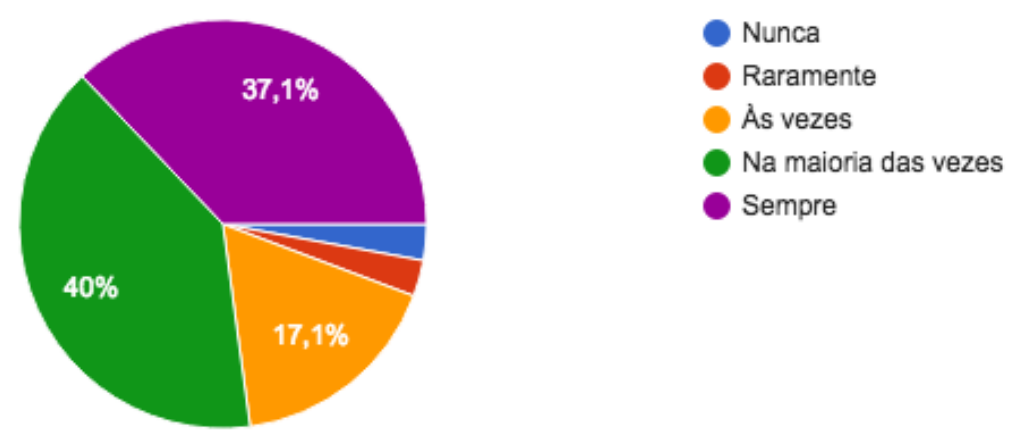

Figura 3: A família sente uma conexão próxima com os profissionais de saúde.
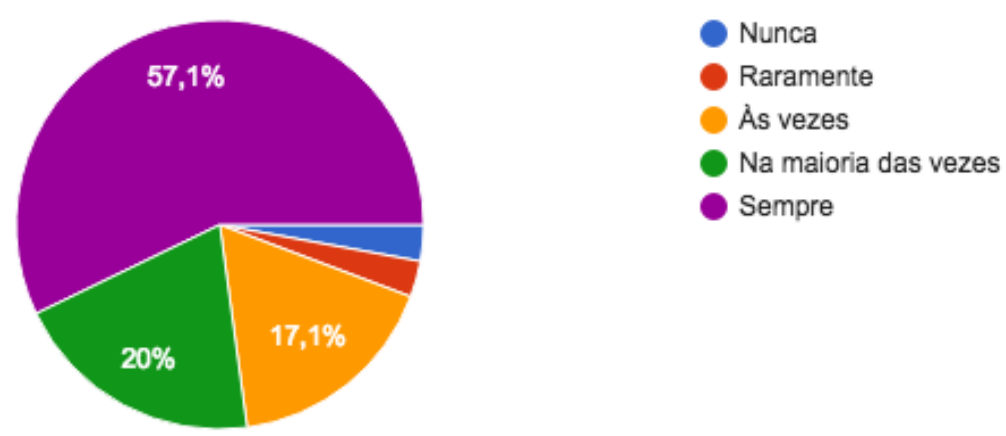

Figura 4: Os profissionais de saúde aceitam a família sem julgamentos 


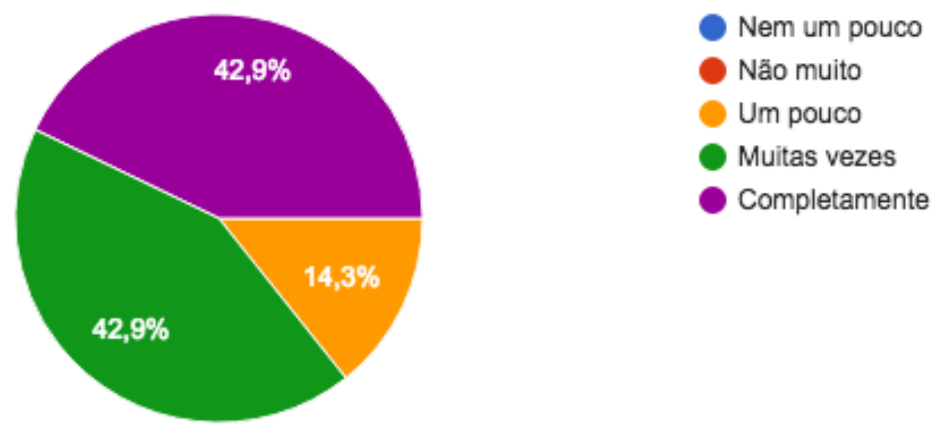

Figura 5: A família confia nos profissionais de saúde

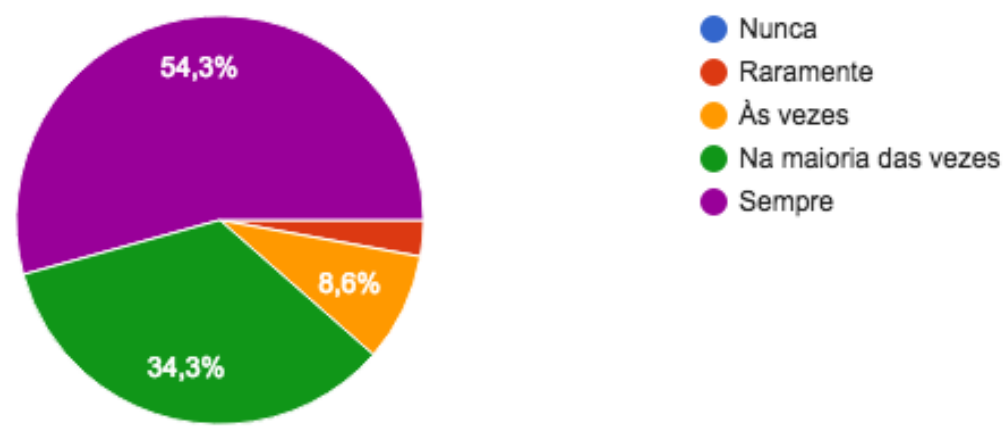

Figura 6: Os profissionais de saúde mostraram seu lado humano

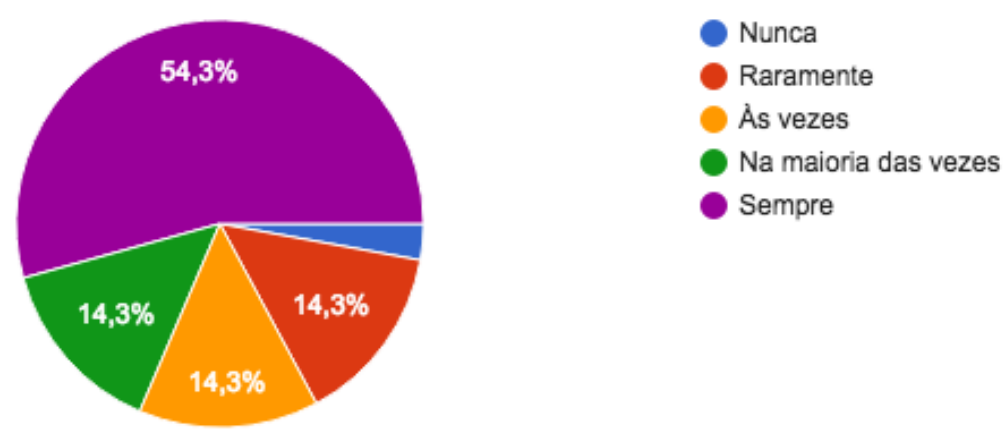

Figura 7: A família e o paciente se sentem como pessoas únicas. 


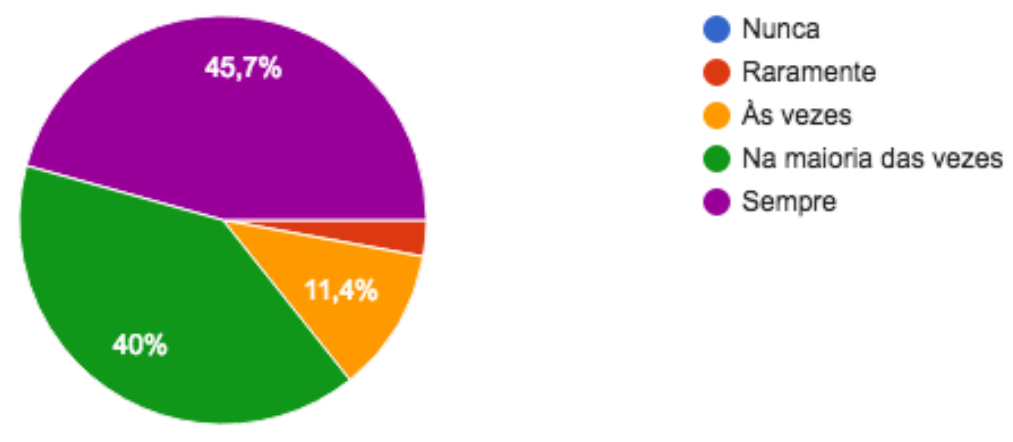

Figura 8: Atos de bondade vindos do profissionais de saúde

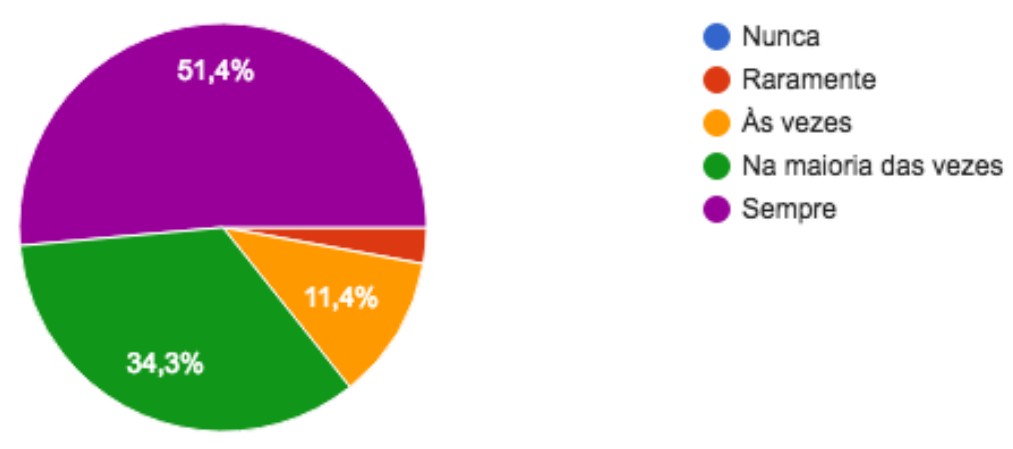

Figura 9: Havia pelo menos um membro da equipe trabalhando constantemente com a família.

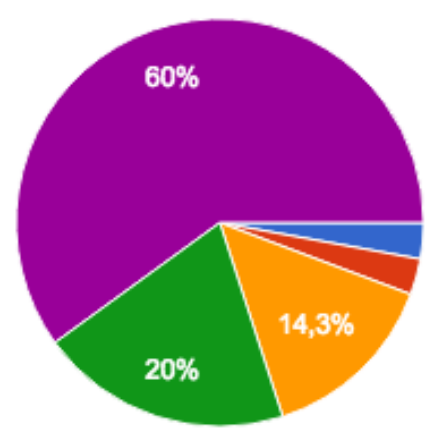

Nunca

Raramente

As vezes

Na maioria das vezes

Sempre

Figura 10: A família sabe qual profissional de saúde está responsável pelo paciente. 


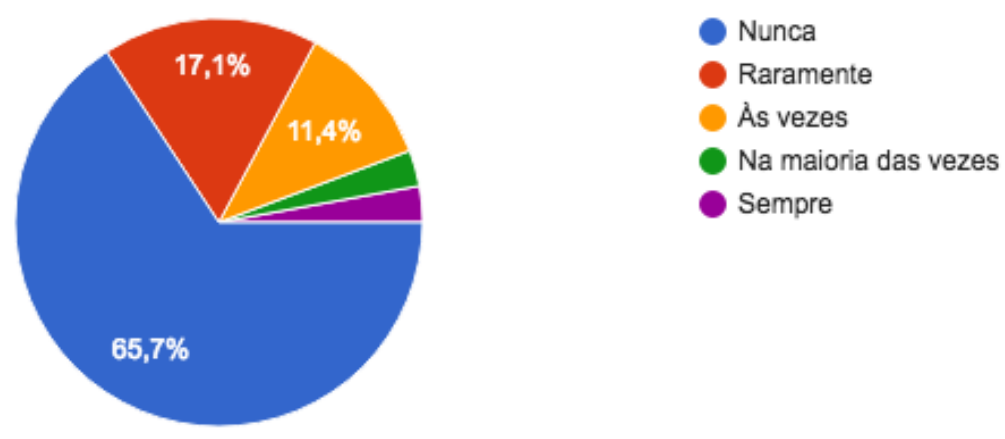

Figura 11: A família sente evitada ou abandonada pelos profissionais de saúde.

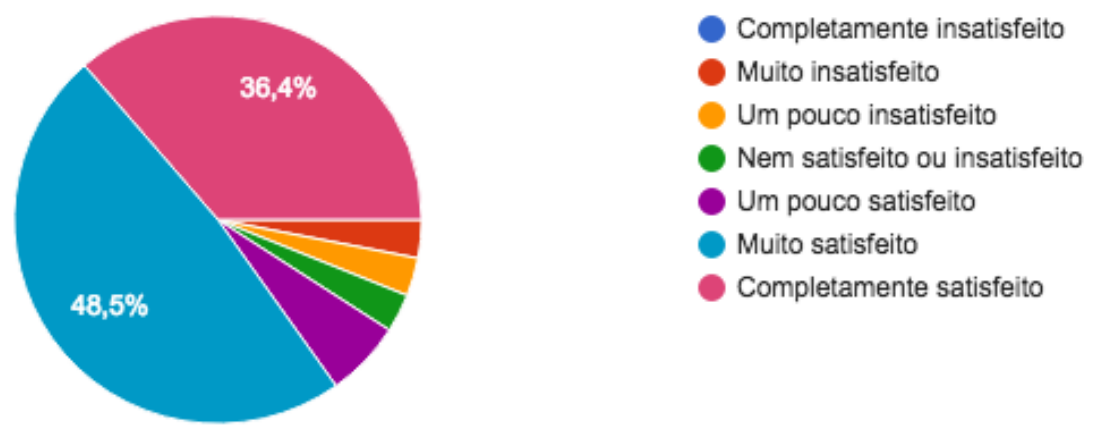

Figura 12: O quão satisfeito a família está com as relações com os profissionais de saúde.

Sobre o domínio de envolvimento dos pais, analisa-se como os pais percebem a possibilidade de fazer parte do cuidado de seu filho. As respostas encontram-se nas figuras de 13 a 18.

Domínio 2 - Envolvimento dos pais: 


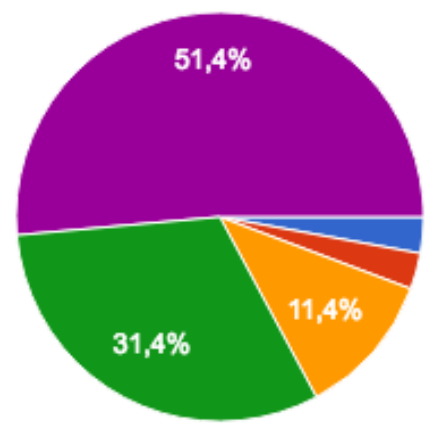

Figura 13: A família é a pessoa que mais conhece o paciente
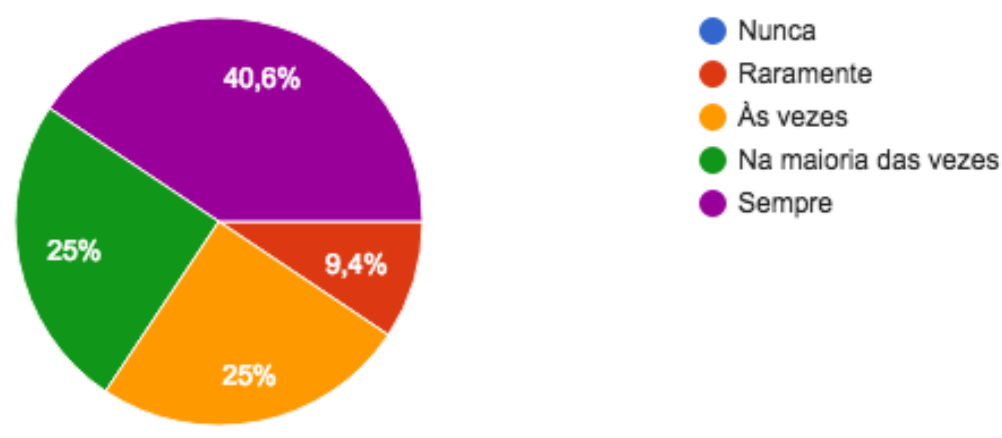

Figura 14: Os profissionais de saúde respeitam os desejos da família

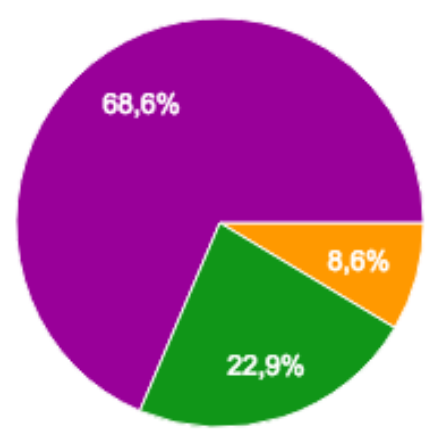

Sempre

Figura 15: Os profissionais de saúde apoiam a família em seu papel de pai/mãe. 


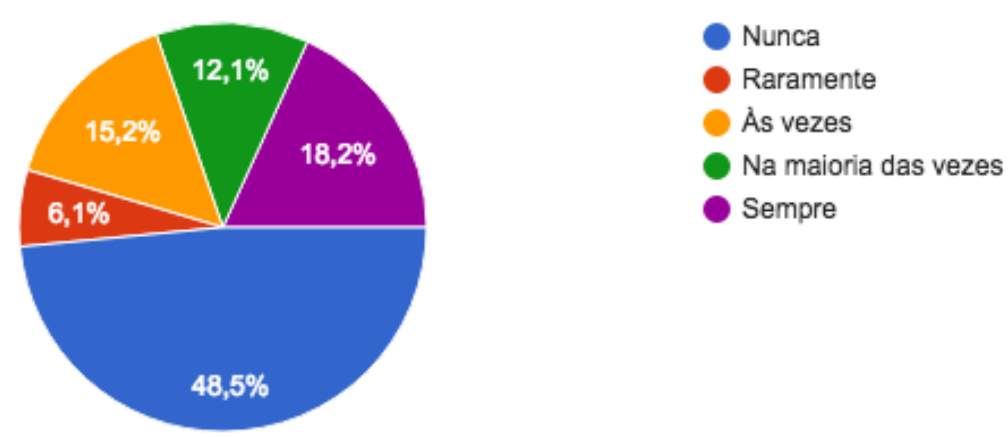

Figura 16: A família tem a opção de permanecer durante um procedimentos difíceis.

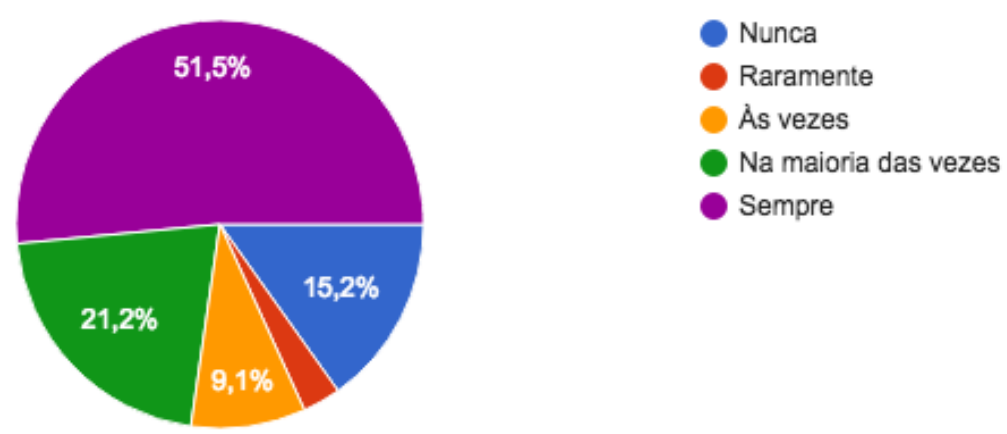

Figura 17: Os profissionais de saúde estão disponíveis para dar apoio à família durante procedimentos difíceis

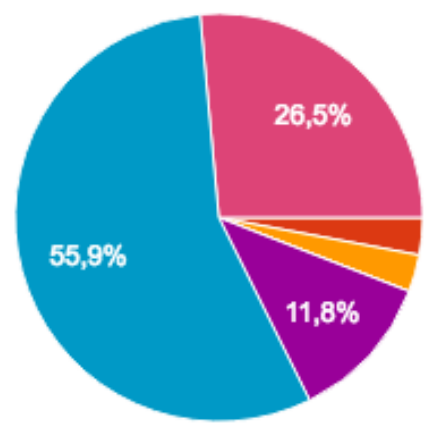

Completamente insatsfeito

Muito insatisfeito

Um pouco insatisfeito

Nem satisfeito ou insatisfeito

Um pouco satisfeito

Muito satisfeito

Completamente satisfeito

Figura 18: A satisfação da família com o seu envolvimento no cuidado do paciente.

Domínio 3 - Compartilhamento de informações com os pais: 
Esse domínio questiona sobre como os pais percebiam o compartilhamento de informações dos profissionais de saúde com eles. As respostas encontram-se nas figuras 19 a 24 .
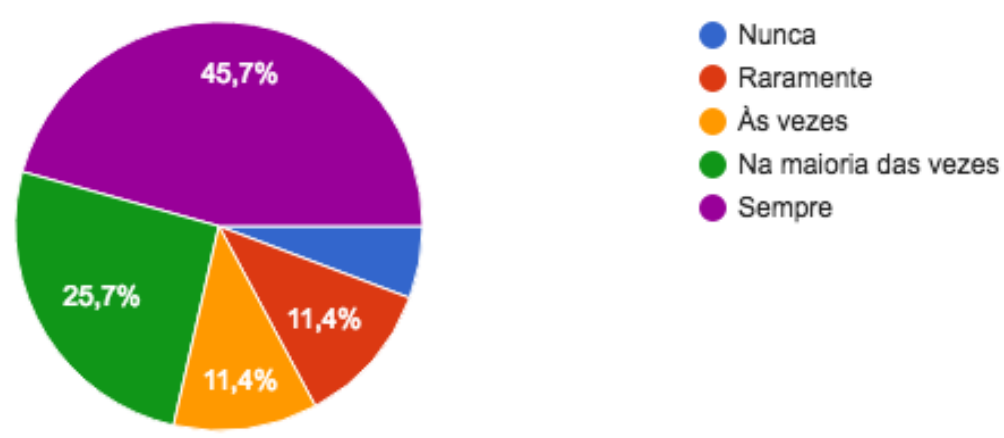

Figura 19: A família tem a opção de escolher a quantidade de informação sobre o quadro do paciente.

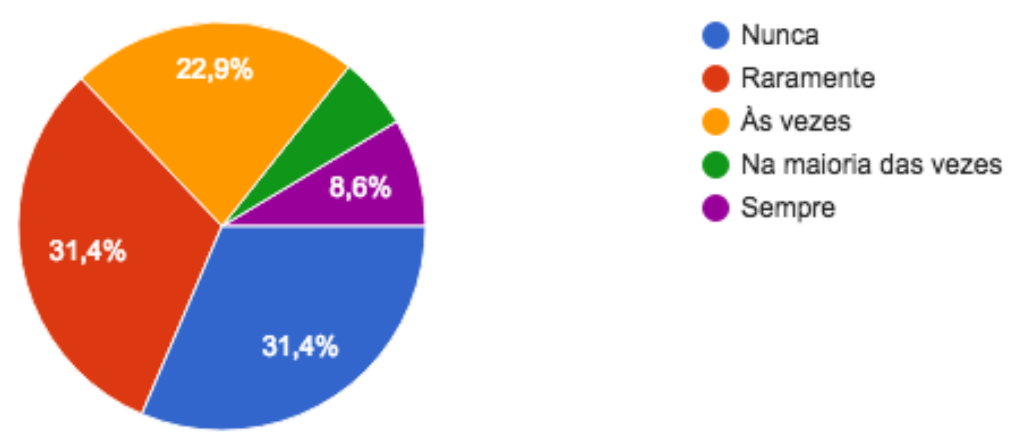

Figura 20: Os profissionais oferecem informações confusas para a família.

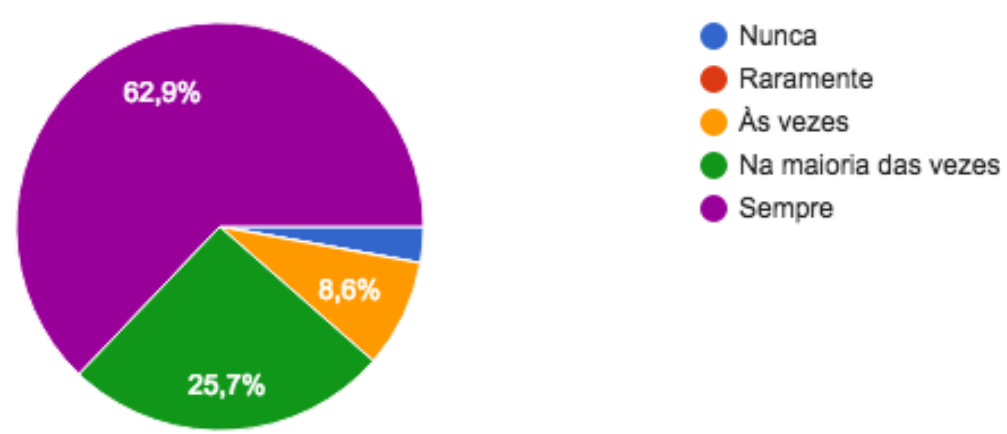

Figura 21: Os profissionais falam sobre o quadro geral do paciente. 


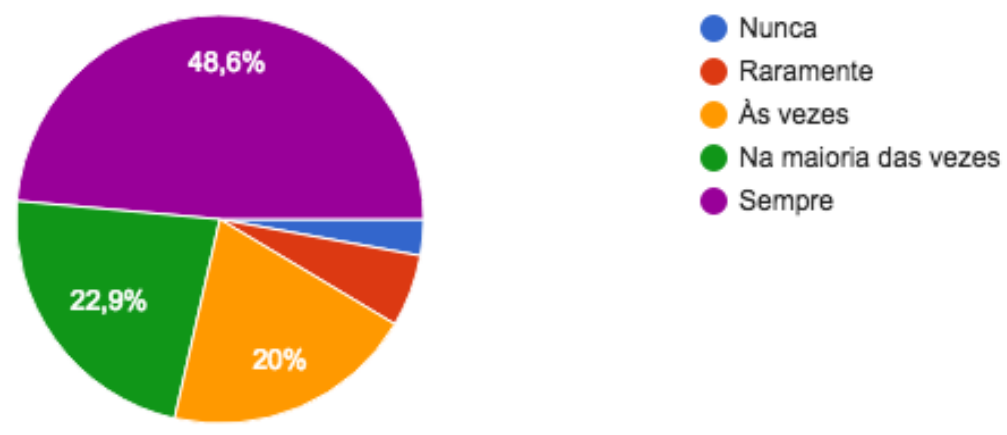

Figura 22: Os profissionais providenciam tempo suficiente para conversar com a família.
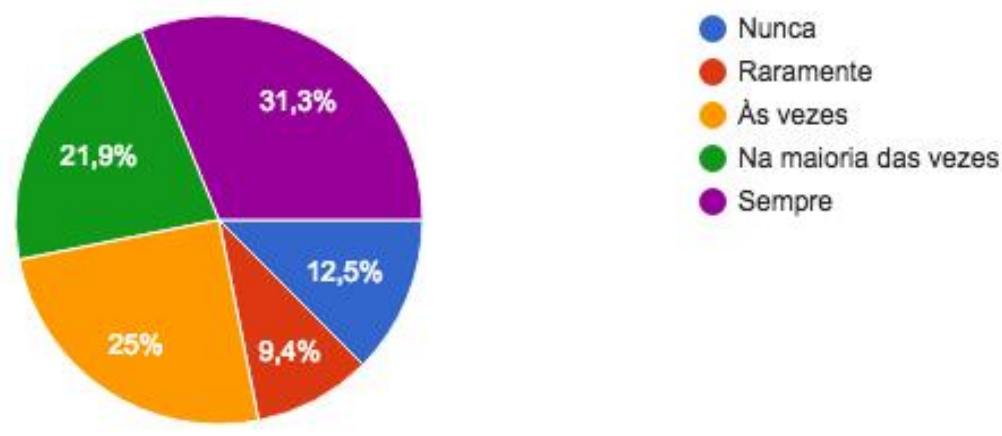

Figura 23: A família participa de encontros com a equipe de saúde sobre o cuidado do paciente.

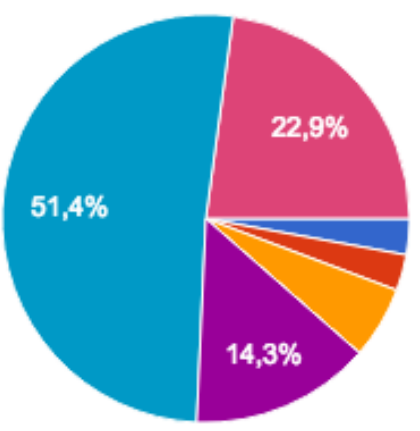

Completamente satisfeito

Figura 24: Satisfação com a informação compartilhada pelos profissionais de saúde 
Estabelecer uma comunicação clara e uma escuta efetiva permite que se compreenda a trajetória da doença e seu impacto nas atividades diárias da criança (BERGSTRAESSER; HAIN; PEREIRA, 2013). Outros aspectos relevantes a serem considerados no cuidado à criança em cuidados paliativos são: o efeito esperado do tratamento direcionado à doença e o impacto do tratamento; o impacto dos sintomas da doença; as preferências do paciente, seus pais e/ou dos profissionais de saúde; e a expectativa de vida (BERGSTRAESSER; HAIN; PEREIRA, 2013).

Domínio 4 - Compartilhamento de informações entre profissionais de saúde:

O quarto domínio refere-se a forma como os pais percebiam o compartilhamento de informações entre os profissionais de saúde. As respostas encontram-se nas figuras 25 a 28 , respectivamente.

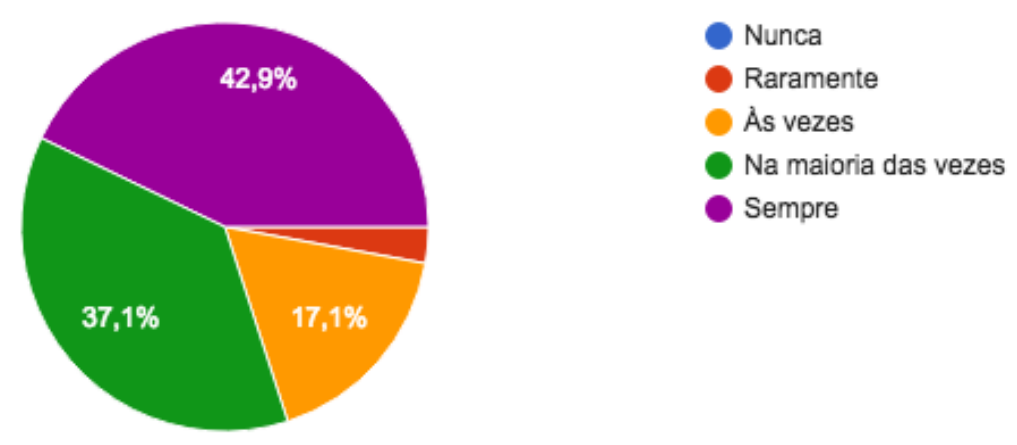

Figura 25: As informações são compartilhadas entre os profissionais da saúde.

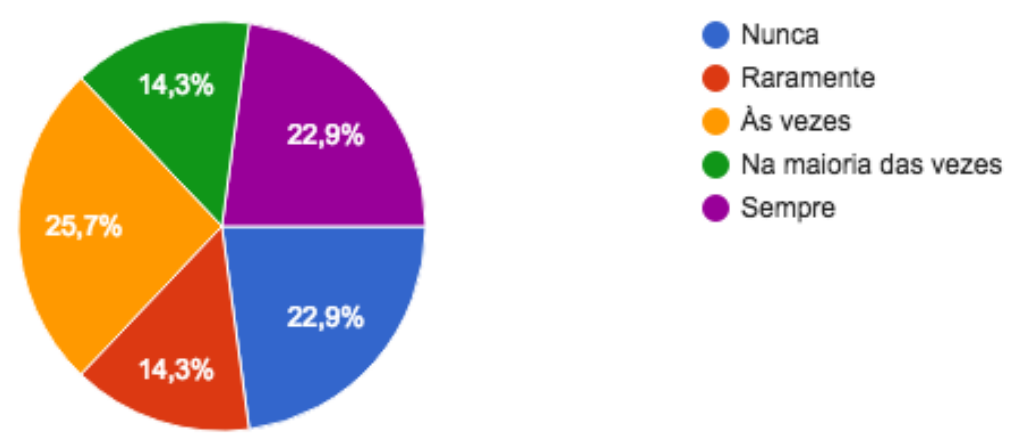

Figura 26: A família que dá informações para os profissionais de saúde sobre a condição do paciente. 


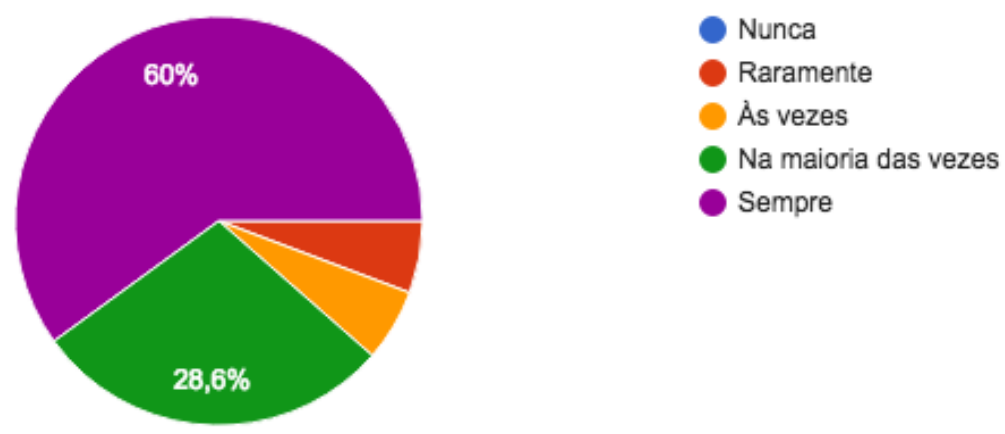

Figura 27: Há um planejamento conjunto dos profissionais de saúde para o cuidado com o paciente.

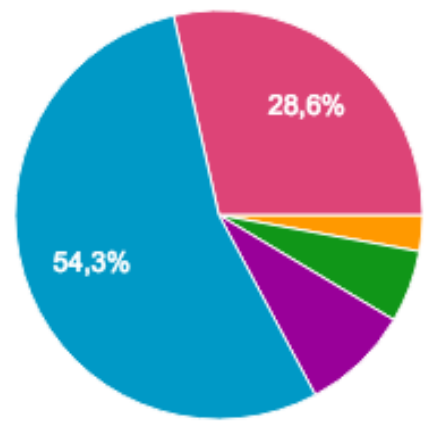

Completamente insatisfeito

Muito insatisfeito

Um pouco insatisfeito

Nem satisfeito ou insatisfeito

Um pouco satisfeito

Muito satisteito

Completamente satisfeito

Figura 28: Satisfação com a informação compartilhada entre profissionais de saúde

Domínio 5 - Suporte à criança:

Trata do estado de saúde da criança, como este é abordado e como envolvem a criança em seu próprio tratamento. As respostas referentes encontram-se nas figuras 29 a 41. 


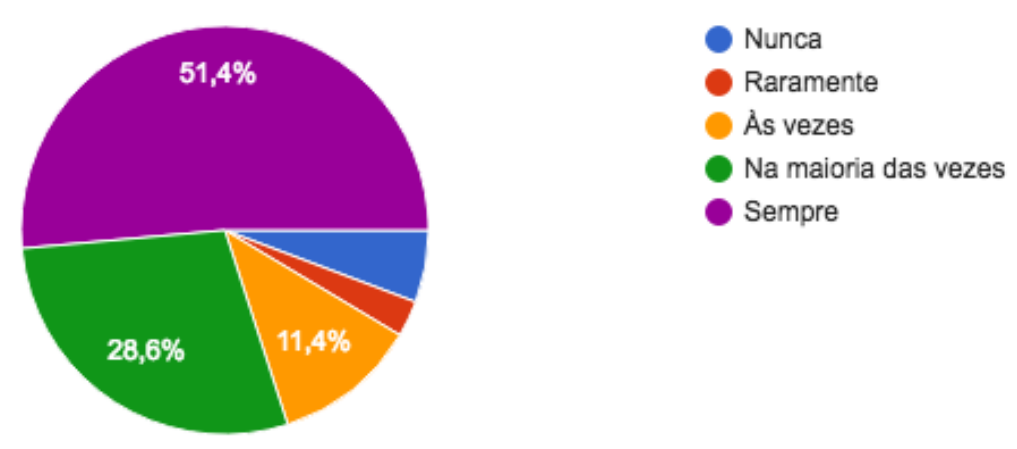

Figura 29: Os profissionais de saúde se atentam a todas às necessidades do paciente (físicas emocionais, sociais, de desenvolvimento e espirituais)
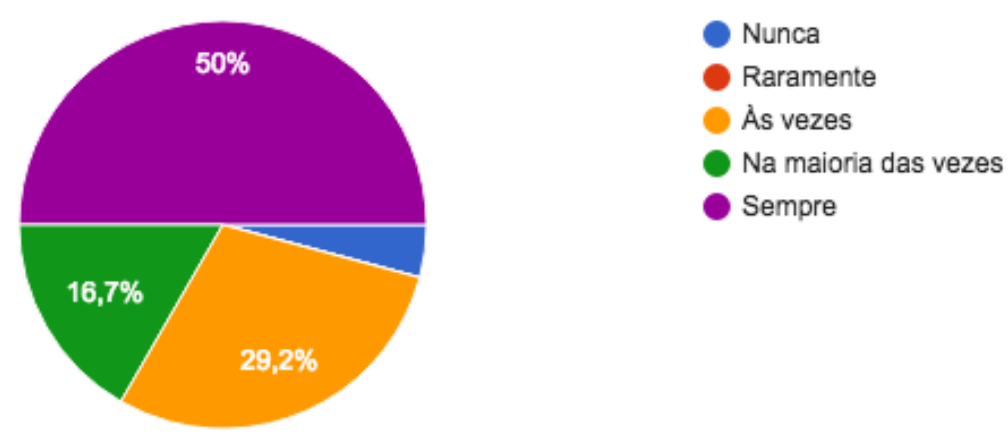

Figura 30: Os profissionais de saúde envolvem o paciente apropriadamente em todas as conversas sobre sua doença.

Os fundamentos dos cuidados paliativos pediátricos são similares ao adulto, porém existem algumas peculiaridades. Segundo VALADARES, MOTA e OLIVEIRA (2013), o cuidado deve ser baseado na tríade paciente-família-profissional de saúde, uma vez que, nessa fase do desenvolvimento a tomada de decisão, muitas vezes, fica mais a cargo da família.

Apesar disso, é importante lembrar que a criança deve ser o foco principal do cuidado e deve ser incluída no processo de cuidado e de tomada de decisão (VALADARES; MOTA; OLIVEIRA, 2013). Segundo Valadares, Mota e Oliveira (2013):

"O desenvolvimento da criança, suas experiências anteriores com a morte, a religião e os aspectos culturais da família são fatores que devem ser considerados para tornar efetiva essa comunicação. Evitar esse tipo de comunicação é ignorar o fato de que as crianças doentes, na maioria das vezes, estão conscientes de sua situação" (p. 490). 


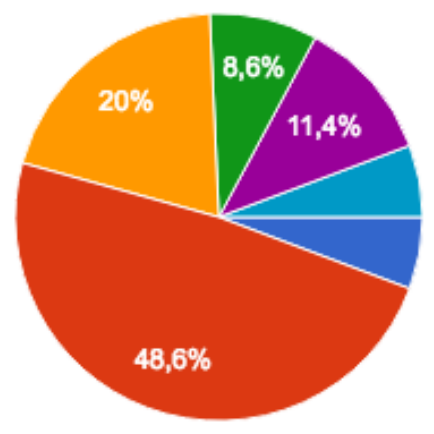

Nem um pouco

Um pouco

Uma quantidade considerável

Muito

Constantemente

Não tenho certeza

Figura 31: O paciente sofreu devido a quadro álgico.

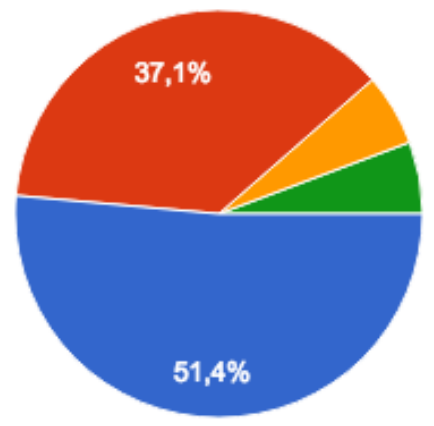

Nem um pouco

Um pouco

Uma quantidade considerável

Muito

Constantemente

Não tenho certeza

Figura 32: O paciente sofreu devido a quadro de náuseas e vômitos.

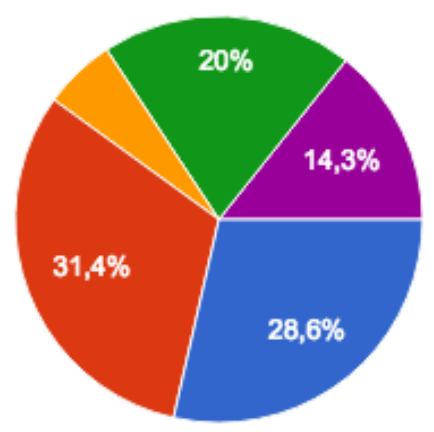

Nem um pouco

Um pouco

Uma quantidade considerável

Muito

Constantemente

Nåo tenho certeza

Figura 33: O paciente sofreu devido a dificuldades respiratórias 


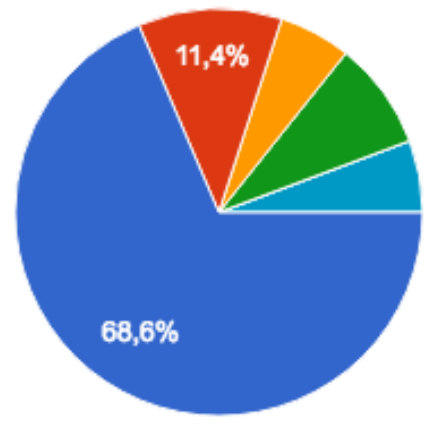

Nem um pouco

Um pouco

Uma quantidade considerável

Muito

Constantemente

Não tenho certeza

Figura 34: O paciente sofreu devido a sangramentos

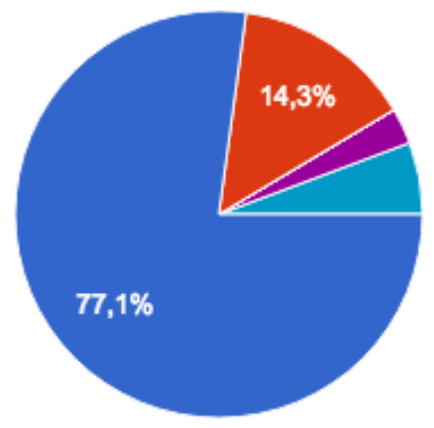

Nem um pouco

Um pouco

Uma quantidade considerável

Muito

Constantemente

Não tenho certeza

Figura 35: O paciente sofreu devido a convulsões

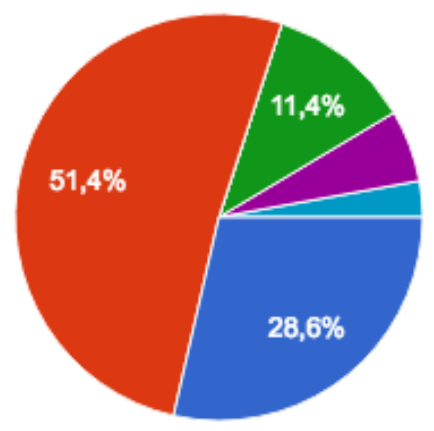

Nem um pouco

Um pouco

Uma quantidade considerável

Muito

Constantemente

Nâo tenho certeza

Figura 36: O paciente sofreu de tristeza 


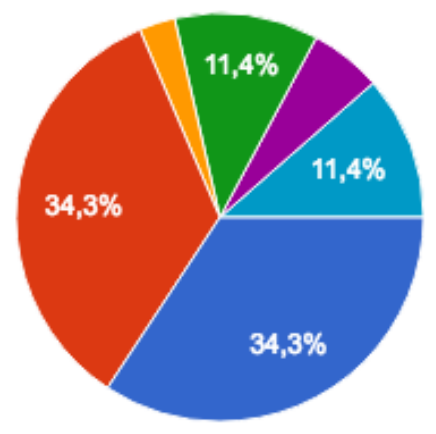

Nem um pouco

Um pouco

Uma quantidade considerável

Muito

Constantemente

Não tenho certeza

Figura 37: O paciente sofreu de ansiedade

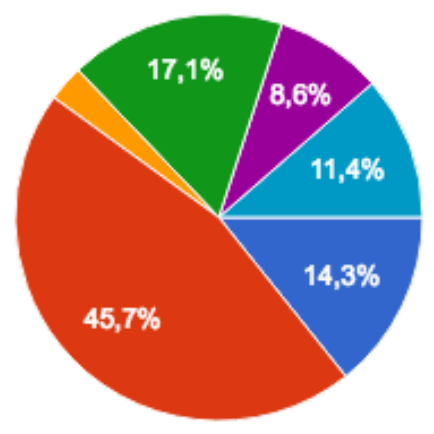

Nem um pouco

Um pouco

Uma quantidade considerável

Muito

Constantemente

Não tenho certeza

Figura 38: O paciente sofreu de medo

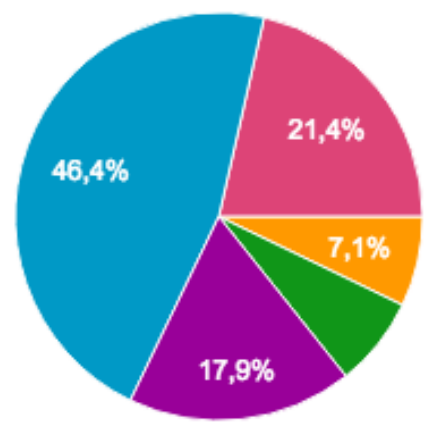

Completamente insatisfeito

Muito insatisfeito

Um pouco insatisfeito

Nem satisfeito ou insatisfeito

Um pouco satisfeito

Muito satisfeito

Completamente satisfeito

Figura 39: Satisfação com a informação compartilhada com o paciente. 


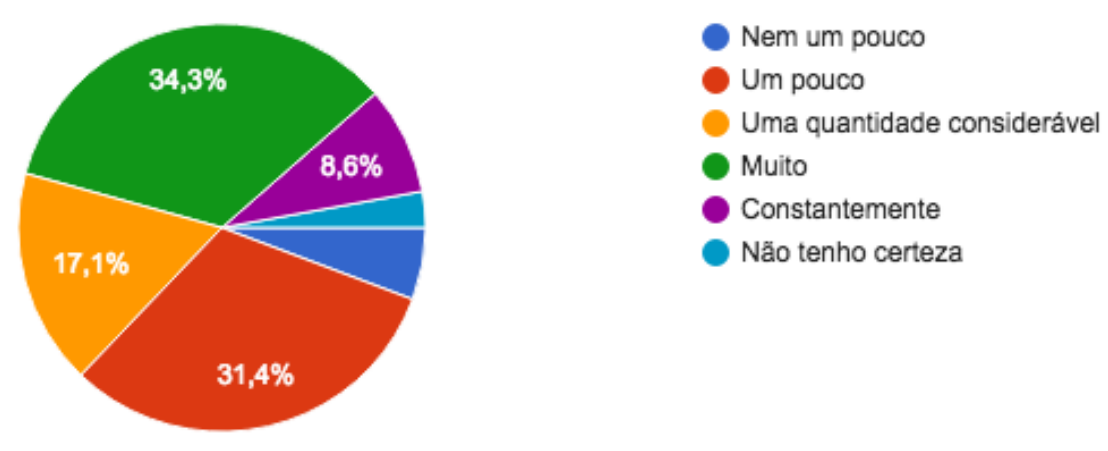

Figura 40: Quantidade de sofrimento do paciente pelos sintomas

$\mathrm{Na}$ assistência ao paciente, o controle dos sintomas configura como a principal estratégia da terapia. Os autores VALADARES, MOTA e OLIVEIRA (2013) relatam que, segundo vários estudos, os sintomas mais recorrentes nos últimos dias de vida dos pacientes pediátricos em cuidados paliativos são dor, fadiga e dispneia, incluindo, também hiporexia, ansiedade, choro prolongado, sonolência, irritabilidade, náuseas, tosse e sintomas psicológicos, como tristeza, nervosismo, irritabilidade e preocupação.

Dessa forma, é essencial que o profissional de saúde tenha um conhecimento mais aprofundado das patologias que causam tais sintomas. Algumas doenças se destacam quanto a necessidade de cuidados paliativos no público infantil são: alterações neurológicas, tumores malignos, má-formação genética/congênita, doenças neuromusculares, doenças respiratórias e gastrointestinais (VALADARES; MOTA; OLIVEIRA, 2013). Compreender sua evolução natural e os sintomas que geram é fundamental para o oferecimento efetivo dos cuidados paliativos.

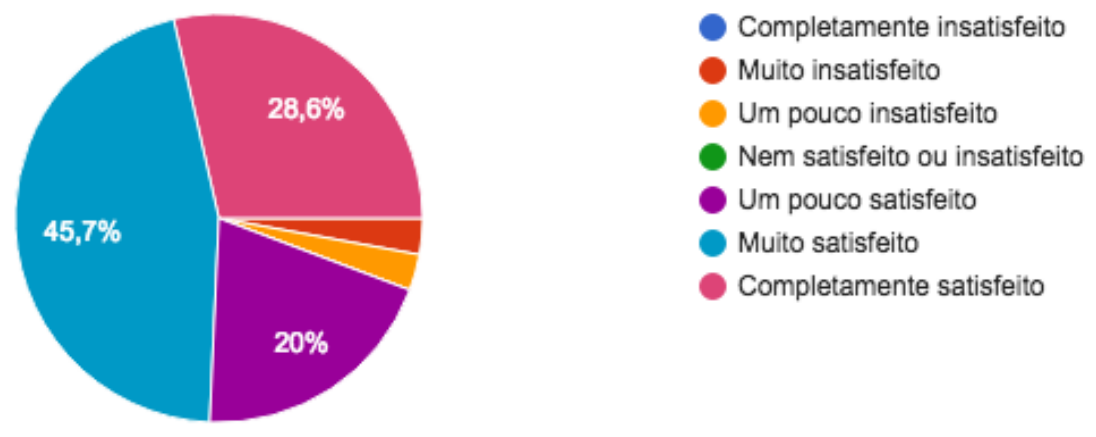

Figura 41: Satisfação com a informação compartilhada com o paciente 
Domínio 6 - Suporte a pais:

Esse domínio aborda o cuidado da equipe de profissionais para com a família do paciente. As respostas encontram-se nas figuras 42 a 47.

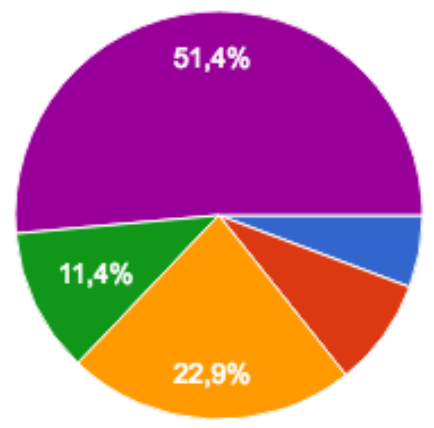

Figura 42: Os profissionais de saúde providenciaram apoio às necessidades emocionais da família

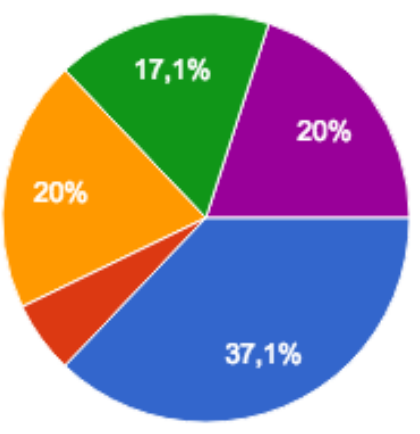

Figura 43: Os profissionais de saúde providenciaram apoio às necessidades espirituais da família 


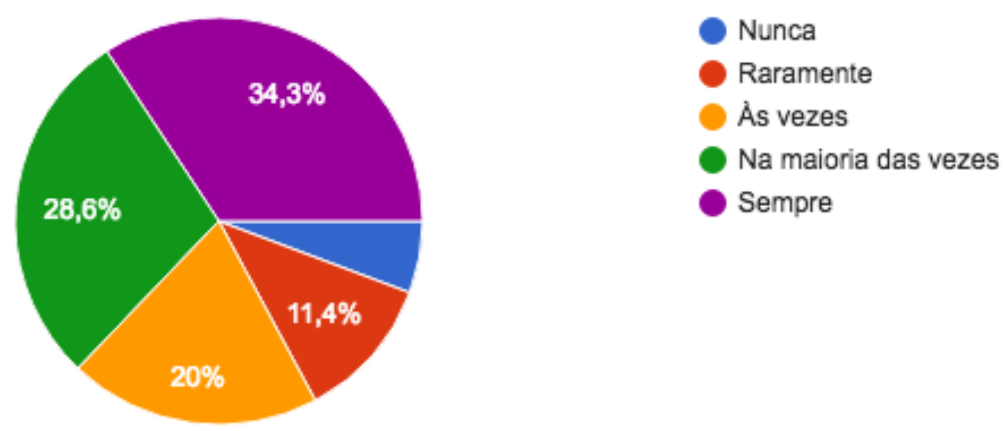

Figura 44: Os profissionais de saúde providenciaram apoio às necessidades sociais da família

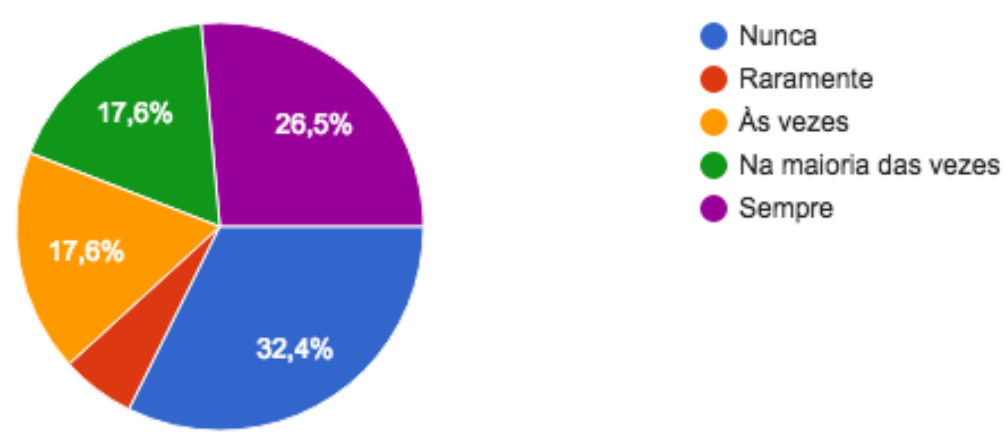

Figura 45: Havia um profissional de saúde como guia apoiando a família

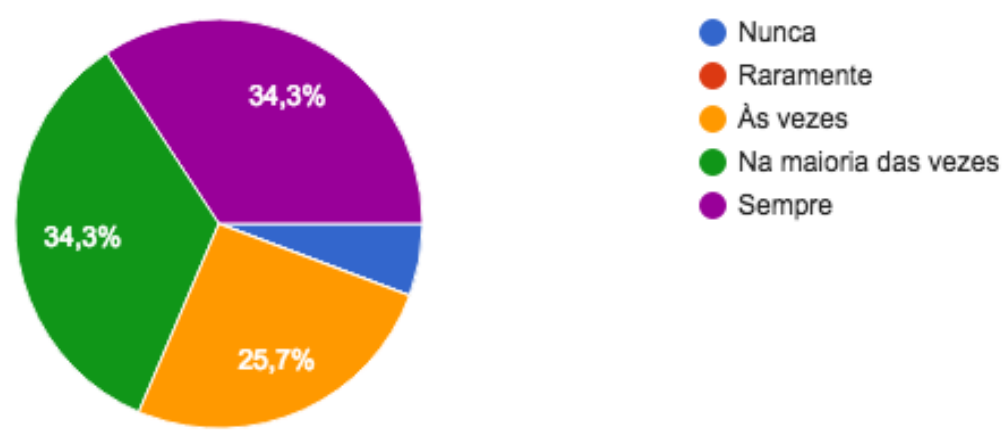

Figura 46: Os profissionais de saúde auxiliavam a encontrar o equilíbrio esperança e planos para um resultado inesperado. 


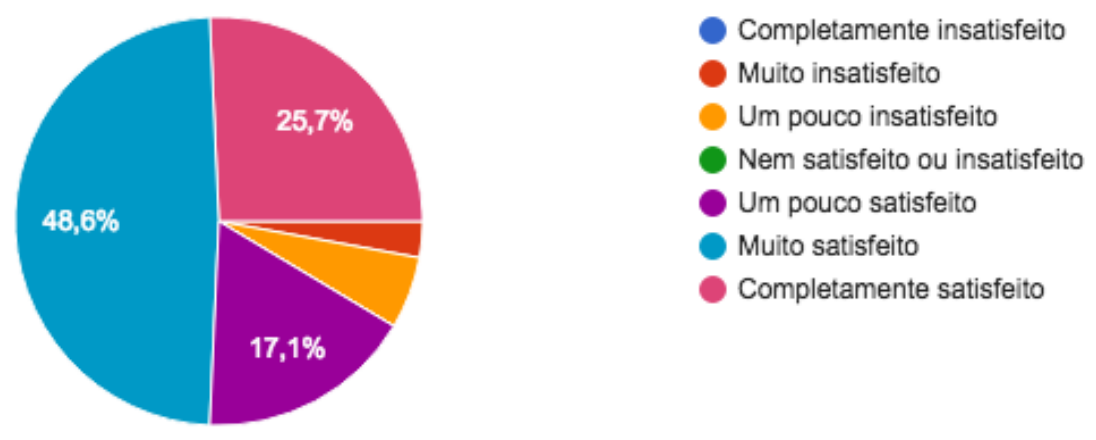

Figura 47: Satisfação com o apoio recebido pelos profissionais de saúde

Qualidade Geral:

O último domínio referia-se à qualidade geral dos cuidados providenciados pela equipe de saúde, levando-se em conta todos os Domínios previamente analisados. O resultado relativo à tal questão encontram-se na figura abaixo:

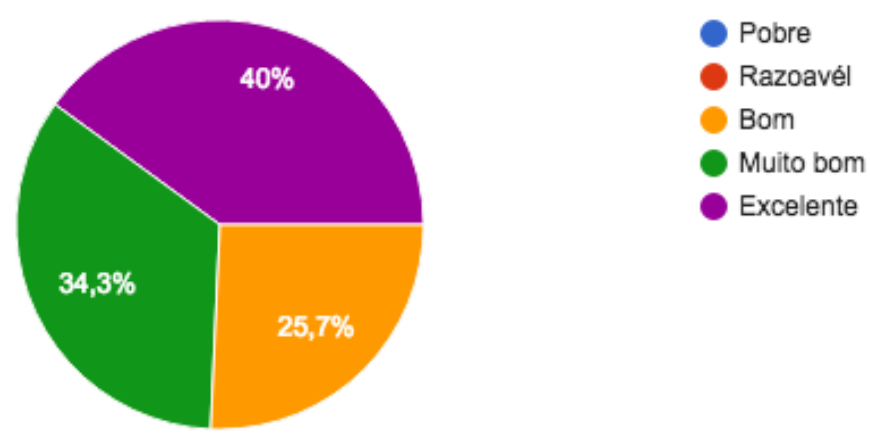

Figura 48: Qualidade geral dos cuidados para com o paciente e sua família

Os cuidados de final de vida devem ser oferecidos em qualquer contexto que possua um paciente em final de vida. Sendo assim, o ambiente de cuidados intensivos pediátricos é um espaço propício a essa forma de cuidar (VALADARES; MOTA \& OLIVEIRA, 2013). O objetivo é oferecer a todas as famílias uma escolha quanto ao estabelecimento de cuidados de fim de vida, principalmente quando se percebe que o tratamento intensivo não irá proporcionar a cura (GUPTA; HARROP; LAPWOOD, 2013).

A integração dos modelos curativo e paliativo pode proporcionar melhor qualidade de vida para as famílias e para os pacientes com doenças crônicas e 
ameaçadoras à vida (VALADARES; MOTA \& OLIVEIRA, 2013). Reconhecer e tratar efetivamente os sintomas mais prevalentes nos pacientes, participar de equipe multidisciplinar, desenvolver bom relacionamento entre a equipe, a família e os pacientes e discutir as questões relacionadas ao final da vida são alguns fundamentos básicos dos cuidados paliativos (VALADARES; MOTA \& OLIVEIRA, 2013).

Dos 35 participantes que responderam ao questionário estruturado da pesquisa, somente 23 concordaram em participar da entrevista com roteiro semi-estruturado. Questionou-se o que aconteceu de melhor, pior e mais importante no cuidado ao paciente.

As respostas referentes aos melhores acontecimentos puderam ser agrupadas em dois grupos: atenção da equipe, que agrupa as falas referentes às atitudes dos profissionais de saúde em relação ao acompanhante do paciente; e procedimento, que contempla práticas médicas. A seguir encontram-se as falas que representam cada categoria.

\section{- Atenção da equipe}

"O suporte, a atenção. Eles têm amor pelo que faz, né. Principalmente dentro da UTI mesmo, eles têm amor pelo que faz. Eles não faz só por virem trabalhar igual a maioria dos empregados faz. Eles gostam do que tão fazendo, principalmente os médicos, faz o que gostam mesmo" (E3).

"A forma como eles explicaram a cirurgia. Esclareceram o que aconteceria daí para frente e o que é fundoplicatura porque eu ainda estava com dúvidas. Eles me ouviam" (E19).

"O suporte que a maioria dos profissionais lhe dão, além da qualificação técnica, é um suporte emocional, que te deixam mais tranquilos quanto aos procedimentos que estão sendo feitos com o seu filho" (E7).

"De melhor, eu achei, assim, a fisioterapeuta. É, eu gostei muito dela. Eu achei que ela deu muito apoio para gente lá. Ajudando a M. a levantar e dar a volta lá. Eu senti muito apoio da parte dela" (E21).

O estabelecimento de uma comunicação efetiva entre pais e profissionais da saúde possibilita aos cuidadores maior conhecimento em relação ao paciente, 
permitindo, assim, que possa tomar parte nos processos decisórios do tratamento (MACK; JOFFE, 2014). Essa situação pode desencadear ansiedade e a depressão cuidadores que participam do processo decisório, isso por quê podem não se sentir confiantes em decidir por outrem, principalmente se não houve acordo prévio de como proceder em tal situação (COOK; ROCKER, 2016).

Compreender o resultado previsto da doença crítica e reconhecer a incerteza dessa previsão é fundamental para a família compreender suas opções e pensar naquela que melhor reflete os valores compartilhados entre eles e o paciente (MACK; JOFFE, 2014; COOK; ROCKER, 2016). Além disso, outros domínios tidos como mais importantes pelos familiares são listados como comunicação genuína; relacionamento sincero e emocional; alívio de sofrimento; suporte espiritual e cultural; continuidade e coordenação do cuidado, acesso ao cuidado; e suporte durante o luto (ZIMMERMANN et al, 2016).

\section{- Procedimento}

"Ah, a cirurgia dele com certeza. É porque ele entrou com um quadro de bronquiolite, né. Aí, já tava atrás da regulação pra poder fazer a cirurgia, que tava bem agravada já a hérnia dele, que podia encarcerar e causar mais dor a ele. E a cirurgia foi o de melhor, que eles já aproveitaram que tava na UTI pra não ter que ir embora, pedir outro leito da UTI pra voltar. Então, já fizeram isso" (E2).

"Que ampliaram a bexiga. A bexiga era pequenininha, não tinha condições de segurar o líquido dentro e, agora, ampliou a bexiga dele. É muito bom pra ele, né?" (E10).

As dos piores acontecimentos em três grupos: profissional, que abrange momentos da relação do cuidador com os profissionais de saúde; ambiente da UTIP, traz as demandas negativas do ambiente de alta complexidade; e más-notícias, refere-se a momentos em que os pais e/ou cuidadores receberam informações de mal prognóstico. A seguir encontram-se as falas que representam cada categoria. 
"Eu acho que a falta de atenção com ele. Alguns profissionais, também, às vezes, a gente conversa, a gente pergunta e eles fingem que não tão ouvindo, ou então, sei lá, se acham superior demais e ignoram. Às vezes, a gente dá uma opinião, a gente fala que o filho tá sentindo, que a gente sabe que o filho da gente tá sentindo e eles simplesmente ignoram" (E2).

"Uma enfermeira que foi grossa. Meu filho chorou e eu perguntei se podia perguntar. Ela foi grossa e disse: 'Tem que perguntar para o médico". Eu pedi lençol para ela e ela disse: 'Calma! Você tem que esperar" (E19).

“De pior, eu acho assim. Eu senti um pouco a falta dos médicos lá. Eu senti mais pessoas mais novas na área, que entendiam um pouco menos, estavam indo aprender. Senti falta dos médicos mais experientes. Eles apareciam de vez em quando, né? A gente sente essa falta, né?' (E21)

Os familiares são a outra ponta da tríade dos cuidados paliativos pediátricos e por isso saber como os cuidadores experienciam o fim de vida de seus filhos, e quais suas necessidades específicas, de maneira a fornecer um cuidado de qualidade (ZIMMERMANN et al, 2016). Para muitos pais, as prioridades na terapêutica paliativa seriam a comunicação completa e verdadeira, o fácil acesso à equipe, o sentimento vivenciado e demonstrado pela equipe, a preservação da integridade da relação paiscrianças e a fé (MEYER et al. 2006).

A boa comunicação é pilar fundamental para estabelecer um bom relacionamento com o paciente e sua família (ANDRADE; COSTA; LOPES, 2013). Ser capaz de ter uma conversa de forma clara e sincera sobre a terminalidade permite estabelecer vínculo e compreender as necessidades dos envolvidos (ANDRADE; COSTA; LOPES, 2013; COOK; ROCKER, 2016). Segundo COOK e ROCKER (2016), a satisfação dos pais com os cuidados oferecidos aos pacientes baseia-se nessa capacidade dos profissionais em transmitir e interpretar as informações de forma efetiva.

- Ambiente da UTIP

"Ver ele lá, todo entubado. Ver ele lá apagado. 
Ter que deixar seu filho quando já tava acordado, deixado ele sozinho acordado pra ir no banheiro. Tem que comer fora, tenho deixado ele sozinho. Isso foi horrivel, porque ele se sente mais, assim, melhor com a mãe, né, a presença da mãe. Aí, ter que deixar ele sozinho lá, sair, isso é horrível. Muitas mães reclamaram também assim pra mim, assim, que não gostam. Às vezes umas ficava lá com fome, pra não deixar teu filho sozinho pra ter que sair pra comer. É horrivel' (E8).

- Más notícias

"O que aconteceu foi a hora que o médico falou que eu ia perder meu filho, que meu filho não ia dá conta de sobreviver. Isso pra mim foi a pior coisa que eu recebi dentro da UTI, a notícia" (E4).

"Quando bateram a TC dele e eu descobri que o cérebro está inchado. Por isso, coma vegetativo" (E16).

É válido ressaltar que a maioria dos pais (56\%) relatou não haver nada de pior, em relação à equipe, durante o período em que o paciente ficou internado. Como exemplificado na fala abaixo:

"O pior que aconteceu mesmo foi o susto, esse susto que ele deu, essa parada cardíaca. Mas, tirando isso, não teve pior não. Todos atendem muito bem, desde o porteiro na entrada do hospital até a saída pelo porteiro também. Todo mundo atende muito bem aqui. Todo mundo. Não tem um que atendeu mal nenhum dos meus familiares, nem meu filho e nem minha esposa" (E3).

Já o que foi mais importante, agrupou-se em três grupos: recuperação, abarca o restabelecimento da saúde da criança; cuidado da equipe, a atenção e o atendimento oferecido pela equipe ao acompanhante do paciente; e qualidade da unidade de saúde, a estrutura do serviço como um todo.

- Recuperação

"Em relação a tudo, o mais importante? Cara, pra mim o mais importante de tudo é o meu filho. Ver ele bem, ver ele sorrindo, é gratificante eu chegar aqui 
e ver ele sorrindo e vê, e não vê o jeito que ele chegou aqui. Ele chegou com falta de ar, tiveram que dar um oxigênio pra ele mais agressivo que a gente não tinha visto ainda. Isso foi ruim. Mas, chegar e ver como ele tá, hoje em dia, pra mim é a coisa mais importante" (E1).

"Que ele vai sair das fralda, né, porque ele usava fralda desde os 12 anos. Agora, que vai fazer 13, agora, ele vai sair das fralda, né, que eu esperava bastante, já ansiosa por esse dia, e esse dia chegou" (E10).

- Cuidado da equipe

"Dentro da UTI, todo o atendimento. Todo atendimento, assim, o geral deles, foi muito importante, porque eles ficaram todo o tempo atento em relação à respiração do meu filho" (E2).

"E ter sentido que, realmente, os médico estavam tentando controlar a dor do meu filho. Então, eu senti que eles, realmente, estavam preocupado com a dor dele" (E5).

"Foi quando eu pedi para conversar com ele depois da reanimação e eles deixaram. Eu fiquei conversando e os batimentos subiram. O pai chegou, chamamos o padre e teve o batismo" (E15).

- Qualidade da unidade de saúde

"Olha, assim, igual eu tô falando, pra mim, aqui, o cuidado que eu tive aqui foi o melhor que eu poderia ter. Porque lá de onde eu venho jamais eu conseguiria. Se eu não tivesse trazido ela pra cá minha filha não teria sobrevivido. Então para mim foi o melhor que poderia ter acontecido" (E14).

"Todos os medicamentos e os exames que fizeram aqui. Se fosse para eu pagar, ele estaria morto, pois eu não teria de onde tirar. $O$ melhor foi $o$ tratamento dele" (E16). 


\section{CONSIDERAÇÕES FINAL}

Indicar cuidados paliativos, precocemente, para todos os pacientes com enfermidades elegíveis ainda é um obstáculo para os profissionais de saúde. Utilizarse de uma ferramenta validada para conhecer a percepção do usuário, quanto a assistência prestada, é de suma importância e pode auxiliar na gestão das UTI e na melhoria de suas práticas.

Esse estudo teve como limitação um curto período de tempo de observação, consequentemente, um $\mathrm{N}$ pequeno. Desse modo, a realidade dessa unidade pode não ter sido completamente retratada. Um estudo mais amplo poderia ser considerado e, também, uma intervenção educativa para melhoria das práticas na instituição de cuidados paliativos. 


\section{REFERÊNCIAS}

1. DA SILVA, Maria Júlia Paes; DE ARAÚJO, Mônica Martins Trovo. Comunicação em cuidados paliativos. Manual de cuidados paliativos ANCP, p. 75, 2012;

2. JOHNSON, M. A Guide to the Development of Children's Palliative Care Services, $3^{\text {a }}$ ed. Bristol, UK: ACT, 2009;

3. MACIEL, Maria Goretti Sales et al. Critérios de qualidade para os cuidados paliativos no Brasil. Rio de Janeiro: Diagraphic, 2006;

4. MENDONÇA, Anna Valeska Procópio de Moura. Cuidados paliativos e serpara-morte: reflexões sobre um atendimento psicológico. 2012. $105 \mathrm{f}$. Dissertação (Mestrado em Psicologia, Sociedade e Qualidade de Vida) Universidade Federal do Rio Grande do Norte, Natal, 2012;

5. HERMES, Hélida Ribeiro; ICA, Lamarca. Cuidados paliativos: uma abordagem a partir das categorias profissionais de saúde. Ciência \& Saúde Coletiva, v. 18, n. 9, p. 2577-88, 2013;

6. BRAGA, Fernanda de Carvalho. Cuidados paliativos em unidade de terapia intensiva neonatal: práticas e percepções de profissionais de saúde. 2013. 124f. Dissertação (Mestrado em Processos de Desenvolvimento Humano e Saúde) - Universidade de Brasília, Brasília, 2013;

7. MEYER, Elaine $C$. et al. Parental perspectives on end-of-life care in the pediatric intensive care unit. Critical care medicine, v. 30, n. 1, p. 226-231, 2002;

8. WIDGER, Kimberley et al. Initial development and psychometric testing of an instrument to measure the quality of children's end-of-life care. BMC palliative care, v. 14, n. 1, p. 1, 2015;

9. LAGO, Patrícia Miranda; GARROS, Daniel; PIVA, Jefferson P. Participação da família no processo decisório de limitação de suporte de vida: paternalismo, beneficência e omissão. Revista Brasileira de Terapia Intensiva, v. 19, n. 3, p. 364-368, 2010;

10.LOTZ, Julia Desiree et al. "Hope for the best, prepare for the worst": A qualitative interview study on parents' needs and fears in pediatric advance care planning. Palliative Medicine, p.1-8, 2016;

11.GULDIN, Mai-Britt et al. Complicated grief and need for professional 
support in family caregivers of cancer patients in palliative care: a longitudinal cohort study. Supportive care in cancer, v. 20, n. 8, p. 1679-1685, 2012;

12. PIVA, Jefferson Pedro; GARCIA, Pedro Celiny Ramos; LAGO, Patrícia Miranda. Dilemas e dificuldades envolvendo decisões de final de vida e oferta de cuidados paliativos em pediatria. Rev bras ter intensiva, v. 23, n. 1, p. 78-86, 2011;

13.JANVIER, Annie; BARRINGTON, Keith; FARLOW, Barbara. Communication with parents concerning withholding or withdrawing of life-sustaining interventions in neonatology. In: Seminars in perinatology. WB Saunders, 2014. p. 38-46;

14. FERREIRA, Roberta Albuquerque. Cuidados paliativos em oncohematologia pediátrica: avaliação psicossocial de cuidadores e percepção de médicos. 2011. 159f. Dissertação (Mestrado em Desenvolvimento Humano e Saúde) - Universidade de Brasília, Brasília, 2011;

15. CUNHA, Cristiane Martins. Avaliação transversal da qualidade de vida de cuidadores de crianças e adolescentes com câncer por meio de um instrumento genérico “36 Item Short Form Health Survey Questionnaire” (SF - 36). 2007. 102f. Dissertação (Mestrado em Ciências da Saúde) Universidade Federal de Uberlândia, Uberlândia, 2007;

16. Associação Nacional de Cuidados Paliativos (ANCP). Programa de residência médica em medicina paliativa do distrito federal. Retirado de http://www.paliativo.org.br/noticias/tag/brasilia/;

17.Beringer, AJ; Heckford, EJ. Was there a plan? End-of-life care for children with life-limiting conditions: a review of multi-service healthcare records. Child: care, health and development, v. 40, n. 2, p. 176-183, 2012;

18. CONNOR, Stephen R.; DOWNING, Julia; MARSTON, Joan. Estimating the Global Need for Palliative Care for Children: A Cross-sectional Analysis. Journal of Pain and Symptom Management, v. 53, n. 2, p. 171-177, 2017;

19. SIM.

Mortalidade infantil

2016.

Retirado

de http://svs.aids.gov.br/dashboard/mortalidade/infantil.show.mtw;

20.KLICK, Jeffrey C.; HAUER, Julie. Pediatric palliative care. Current problems in pediatric and adolescent health care, v. 40, n. 6, p. 120-151, 2010; 
21. World Health Organization. (2017, Abril). Who definition of palliative care [website]. Recuperado de http://www.who.int/cancer/palliative/en/;

22. American Academy of Pediatrics Committee on Bioethics and Committee on Hospital Care. Palliative care for children. Pediatrics 2000;106(Pt 1):351-7;

23. HILMELSTEIN, Bruce P. Palliative care for infants, children, adolescents, and their families. Journal of palliative medicine, v. 9, n. 1, p. 163-181, 2006;

24.ÁRIES, Philippe. (2003). História da morte no ocidente. Rio de Janeiro: Editouro;

25. BARBOSA, Silvia Maria de Macedo (2012). Cuidado Paliativo em Pediatria. In Associação Brasileira de Cuidados Paliativos (Ed.), Manual de Cuidados Paliativos ANCP (pp. 461-473). Ampliado e Atualizado. 2ª ed. Rio de Janeiro: ANCP;

26. MILLER, Elissa G. et al. Pediatric palliative care: current evidence and evidence gaps. The Journal of pediatrics, v. 166, n. 6, p. 1536-1540. e1, 2015;

27. KNAPP, Caprice A. et al. Family support in pediatric palliative care: how are families impacted by their children's illnesses?. Journal of palliative medicine, v. 13, n. 4, p. 421-426, 2010;

28. FEUDTNER, Chris et al. Parental hopeful patterns of thinking, emotions, and pediatric palliative care decision making: a prospective cohort study. Archives of pediatrics \& adolescent medicine, v. 164, n. 9, p. 831-839, 2010;

29. AL-GHARIB, Rania Mosleh; ABU-SAAD HUIJER, Huda; DARWISH, Hala. Quality of care and relationships as reported by children with cancer and their parents. Annals of palliative medicine, v. 4, n. 1, p. 22-31, 2015;

30.SNAMAN, Jennifer M. et al. Helping parents live with the hole in their heart: The role of health care providers and institutions in the bereaved parents' grief journeys. Cancer, v. 122, n. 17, p. 2757-2765, 2016;

31. NAMACHIVAYAM, Poongundran et al. Three decades of pediatric intensive care: Who was admitted, what happened in intensive care, and what happened afterward. Pediatric Critical Care Medicine, v. 11, n. 5, p. 549-555, 2010;

32. STEVENS, Michael M. et al. Research with vulnerable families caring for children with life-limiting conditions. Qualitative health research, v. 20, n. 4, p. 496-505, 2010;

33. FONTELLES, Mauro José et al. Metodologia da pesquisa científica: 
diretrizes para a elaboração de um protocolo de pesquisa. Revista Paraense de Medicina, v. 23, n. 3, p. 1-8, 2009;

34. ALMEIDA FILHO, N. de; ROUQUAYROL, M. Z. Introdução à epidemiologia. 4. ed. Rio de Janeiro: Guanabara Koogan, 2006;

35. BARDIN, Laurence. Análise de conteúdo. (1977). Lisboa (Portugal): Edições, v. 70, 2010.

36. COOK, Deborah; ROCKER, Graeme. Dying with Dignity in the Intensive Care Unit. New England Journal of Medicine, v. 370, n. 26, p. 2506 - 2514, Jun. 2016.

37. KELLY, John A; MAY, Carol S; MAURER,Scott H. Assessment of the Spiritual Needs of Primary Caregivers of Children with Life-Limiting Illnesses Is Valuable Yet Inconsistently Performed in the Hospital. Journal of Palliative Medicine, v. 19, n. 7, p. 763-766, Jul. 2016.

38.BERGSTRAESSER, Eva; HAIN, Richard D.; PEREIRA, José L. The development of an instrument that can identify children with palliative care needs: the Paediatric Palliative Screening Scale (PaPaS Scale): a qualitative study approach. BMC palliative care, v. 12, n. 1, p. 20, Mai. 2013.

39. VALADARES, Maria Thereza Macedo; MOTA, Joaquim Antônio César; OLIVEIRA, Benigna Maria. Cuidados paliativos em pediatria: uma revisão.

Revista de Bioética, v. 21, n. 3, p. 486-493, Set./Dez. 2013.

40.GUPTA, Neelam; HARROP, Emily; LAPWOOD, Susie; SHEFLER, Alison. Journey from Pediatric Intensive Care to Palliative Care. Journal of Palliative Medicine, v. 16, n. 4, Abr. 2013.

41. MACK, Jennifer W.; JOFFE, Steven. Communicating about prognosis: ethical responsibilities of pediatricians and parents. Pediatrics, v. 133, Supplement 1, p. S24-S30, Fev. 2014.

42. ZIMMERMANN, Karin et al. When parents face the death of their child: a nationwide cross-sectional survey of parental perspectives on their child's endof life care. BMC palliative care, v. 15, n. 1, p. 30, Mar. 2016.

43. ANDRADE, Cristiani Garrido de; COSTA, Solange Fátima Geraldo da; LOPES, Maria Emília Limeira. Cuidados paliativos: a comunicação como estratégia de cuidado para o paciente em fase terminal. Ciência \& Saúde Coletiva, v. 18, n. 
9, p. 2523 - 2530, Set. 2013. 